\title{
EXPERIENCIAS CONSTRUCTIVAS DEL TERREMOTO DE LORCA
}

\author{
José-Carlos Salcedo Hernández \\ Departamento de Construcción \\ Universidad de Extremadura \\ Antonio-José Campesino Fernández \\ Departamento de Arte y Ciencias del Territorio \\ Universidad de Extremadura
}

In memoriam de los fallecidos en Lorca

\section{RESUMEN}

El terremoto de Lorca del 11 de mayo de 2011 es el más importante que ha sufrido el territorio peninsular español en los últimos 55 años, desde el terremoto de Albolote (Granada) de 1956 que, casualmente, fue del mismo tipo y tuvo idéntica magnitud de 5,1 grados en la escala Richter.

En estos 55 años, la tipología de los edificios ha cambiado completamente, pasando de edificios de muros de fábrica de hasta dos plantas de altura, a la generalización de edificios de pisos de una media de 6 plantas, de pilares y vigas con nudos rígidos y forjados de hormigón. Es importante extraer experiencias constructivas del comportamiento que han tenido los edificios de Lorca, porque es el único caso real de que disponemos, para la mejora de la seguridad estructural antisísmica de los edificios en España.

En Lorca se ha constatado el mal comportamiento de las estructuras de fábrica de ladrillo con las que está construido el patrimonio histórico. Se ha probado que, con la sola excepción de un edificio, las estructuras nuevas de hormigón y acero han superado una aceleración sísmica del triple de la prevista por la norma sismorresistente NCSE-02, con la que fueron calculadas. Por el contrario, se ha constatado un pésimo comportamiento de los elementos de fábrica (petos, cerramientos, tabiques, etc, de ladrillo) con fracasos generalizados, que son los que produjeron los enormes daños materiales en las viviendas y los daños personales. Estos elementos no son «estructurales», pero la norma NCSE-02 establecía para ellos unas condiciones que no debieron aplicarse en las construcciones realizadas desde su implantación. Lorca.

Palabras-clave: patología, patrimonio, construcción, seguridad estructural, sismo, 


\section{ABSTRACT}

The Lorca earthquake of May 11, 2011, is the most important event that has affected the Spanish mainland in the last 55 years, since the earthquake of Albolote (Granada) in 1956 which, interestingly, was the same type and had the same magnitude of 5,1 degrees on the Richter scale.

In these 55 years, the typology of the buildings has changed completely, from buildings of masonry walls up to two storeys high, the generalization of apartment buildings from an average of 6 floors, columns and beams whith rigid joints and concrete floors. It is important to make constructive behavioral experiences that have buildings Lorca, it is the only real case we have, for the improvement of seismic structural safety of buildings in Spain.

Lorca has been found in the bad behaviour of the brick structures with which it is built heritage. It has been proved that with the exception of a building, the new structures of concrete and steel seismic acceleration has exceeded three times the standard prescribed by seismic NCSE-02, which were calculated. By contrast, there has been the worse performance of the factory elements (bibs, fences, walls, etc, brick) with widespread failures, which are those that produced the enormous damage to housing and personal injury. These elements are not «structural» but the NCSE-02 standard set for them conditions that have not implemented in buildings constructed since the adoption of this standard.

Keywords: pathology, heritage, construction, structural safety, earthquake, Lorca.

\section{La actividad sísmica y los edificios}

\subsection{La importancia de la experiencia sobre los terremotos.}

El análisis del comportamiento real de las construcciones, en los escasos terremotos importantes sucedidos en la dinámica sísmica reciente de la Península Ibérica, arroja importantes conclusiones para valorar la seguridad estructural de los edificios construidos y para conseguir mejorarla en el futuro.

La ingeniería estructural de edificación es una técnica (una ciencia aplicada) y, por tanto, su principal base de conocimiento la proporciona la experimentación, más que el análisis con hipótesis de cálculo que, aunque sean aplicables a los edificios nuevos, no sirven para explicar el comportamiento de las estructuras antiguas de fábrica que, en cambio, sí pueden ser correctamente diagnosticadas a partir de su comportamiento real ante los terremotos.

Cada terremoto afecta de forma diferente a las construcciones, porque influyen múltiples factores, desde las especificidades tectónicas del terremoto, a la composición litológica del suelo urbano y a las características de las estructuras de los edificios. Contamos con tres terremotos especialmente importantes para la ingeniería estructural en España: el de Lisboa (1755), el de Albolote (1956) y el de Lorca (2011).

El macrosismo de Lisboa ${ }^{1}$ (1755), considerado de $8^{\circ}$ a $9^{\circ}$ de magnitud Richter, se produjo fuera de la Península, a más de $300 \mathrm{~km}$ al S-SO del Cabo de San Vicente y, sin embargo, ocasionó en España muertos e importantes daños en muchas estructuras de fábrica de mampostería de torres y cruceros de catedrales, grandes iglesias y murallas en el cuadrante SO de la Península, aunque pocos daños en el caserío popular.

1 A este sismo se le denomina «de Lisboa», porque entre el terremoto, el maremoto y el incendio posterior, Lisboa fue la ciudad más afectada, con decenas de miles de muertos. 
El de Albolote (Granada) de 1956, fue un sismo de fallas (muy alejado de zonas de subducción), de «sólo» $5,1^{\circ}$ de magnitud Richter pero que, al producirse bajo el mismo núcleo de población, arrasó el caserío, que estaba construido con muros de fábrica de mampostería y de tapial, y un máximo de dos plantas de altura. El terremoto de Lorca (9 muertos) y el de Albolote (11 muertos) son los mayores terremotos con víctimas mortales ${ }^{2}$ sucedidos en España desde el s. XX.

Pero las experiencias constructivas más importantes para la ingeniería sismorresistente en España se podrán extraer ahora del sismo de Lorca (2011) por una sencilla razón: es la primera vez en la historia que los edificios actuales, de estructuras de pisos, con pórticos de nudos rígidos, de forjados de hormigón y de varias plantas de altura (del orden de 6), son sometidos a una aceleración sísmica tan importante. El terremoto de Lorca es idéntico (en lo que a la acción contra los edificios se refiere) al de Albolote, pues han coincidido tanto la magnitud $\left(5,1^{\circ}\right.$ Richter), como la aceleración sísmica $(0,36-0,37 \mathrm{~g})$, pero afectando a una forma de construir totalmente distinta, que denominaremos genéricamente en este artículo «construcción moderna».

En el terremoto de Lorca, por primera vez en España, se ha puesto a prueba la seguridad antisísmica de los edificios nuevos, con un resultado satisfactorio desde el punto de vista de la seguridad estructural (de los más de 3.000 edificios nuevos sólo dos $^{3}$ de sus estructuras no superaron las acciones) y protegieron bien a sus ocupantes. Pero el episodio sísmico de Lorca arroja también información inédita sobre el mal comportamiento de los elementos constructivos, que se denominan «secundarios»: los fallos en estos elementos no estructurales han sido demasiado generalizados, produciéndose elevados daños materiales y siendo además responsables de un inesperado número de muertos, que ha sorprendido a nuestra sociedad y que se produjo fuera de los edificios, en la calle.

Los tres terremotos citados (Lisboa, Albolote y Lorca) representan, además, a las tres zonas de mayor sismicidad de la España peninsular: zona de Huelva, zona de Granada y zona de Murcia.
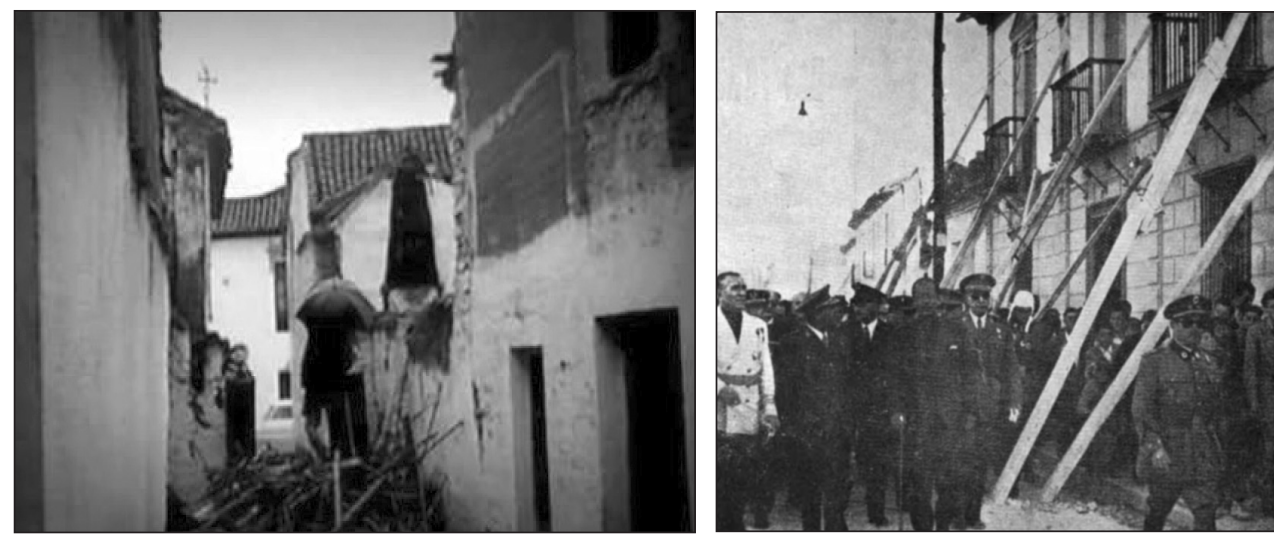

FIGURAS 1 y 2. Daños del terremoto de Albolote (1956), que afectó a un pueblo con construcciones de muros de fábrica de mampostería de piedra y tapial, de una y dos plantas de altura. Fuente: NO-DO.

2 Adscrito a la misma zona sísmica, el terremoto de Agadir (Marruecos), de 29 de febrero de 1960, de $5,7^{\circ}$, destruyó la ciudad de la fachada atlántica marroquí y ocasionó 15.000 muertos.

3 Un edificio que colapsó coincidiendo con el sismo y otro que se hundió unos días después ante una mínima acción de las máquinas, y que son consideradas las dos únicas estructuras modernas colapsadas por el terremoto. 


\subsection{Actividad sísmica en la comarca de Lorca}

Los terremotos del SE español son producto de la dinámica tectónica de las placas litosféricas Euroasiática y Africana (con acercamiento de 4,5 mm/año), que colisionan a lo largo del eje atlántico-mediterráneo (área Ibero-Mogrebí) entre las Azores y Siria. Sus fricciones liberan energía a través de las fallas activas cuaternarias en forma de terremotos o de emisiones magmáticas.

La ciudad de Lorca, de 92.869 habitantes (INE, 01-01-2011), se emplaza sobre la falla de desgarre de Alhama de Murcia, de dirección NE-SO y 85 km de longitud ${ }^{4}$, con sus fallas asociadas, activas y complejas. Sobre los depósitos aluviales y coluviales de la cuenca sedimentaria del valle del Guadalentín (que amplifican la señal del tren de ondas sísmicas), las fallas atraviesan el subsuelo del casco urbano en los sectores de Plaza de España, barrio de La Viña y falda Norte del cerro del Castillo (Martínez-Díaz, 1999).

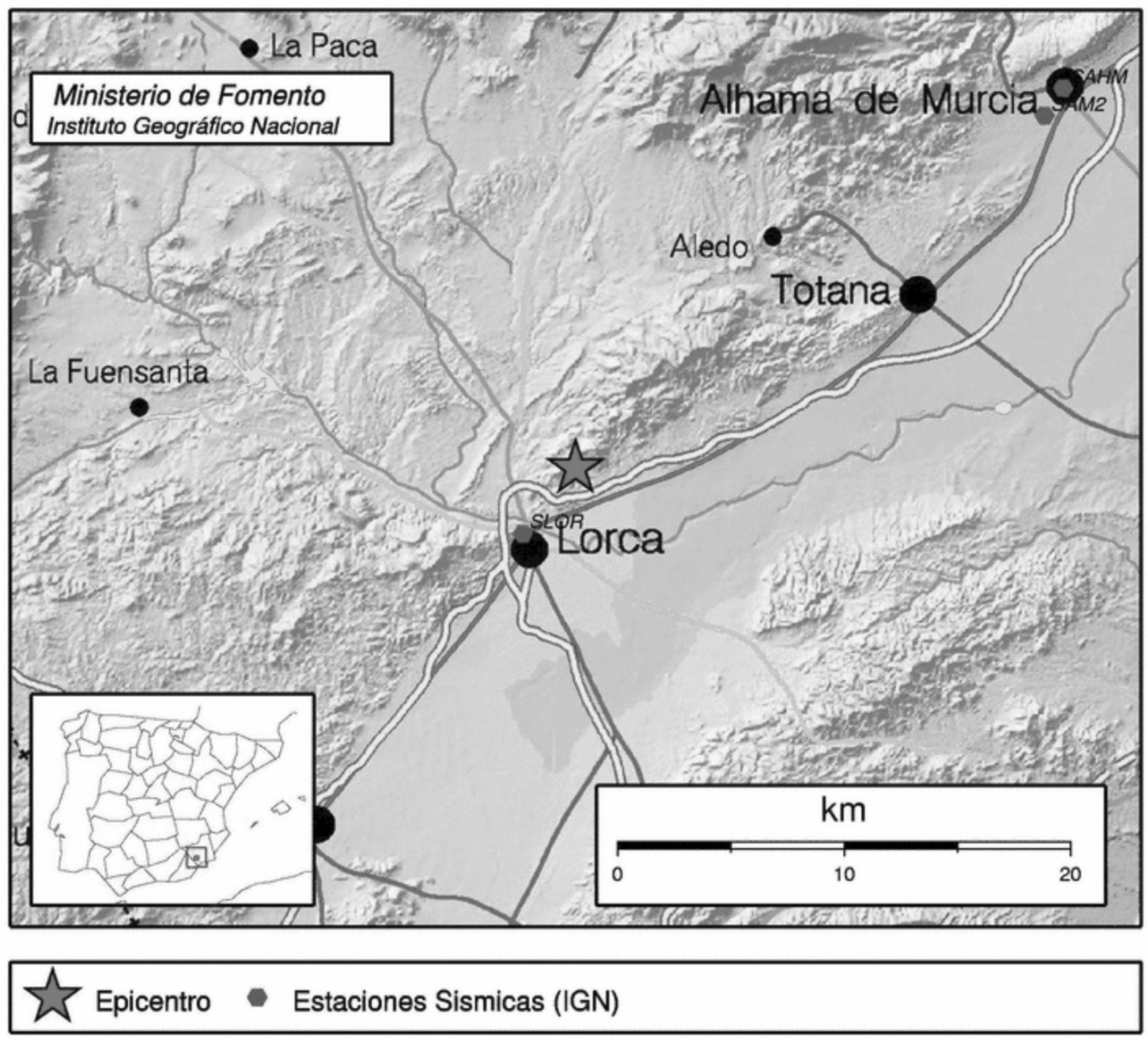

Figura 3. Mapa de la zona del terremoto. Fuente: Ministerio de Fomento. IGN.

4 Las fallas con mayor potencial para producir terremotos importantes son aquellas de mayor longitud, ya que la magnitud de un terremoto depende directamente de la longitud de ruptura de la falla que lo genera (Cabañas et al., 2011; 11). 
Dejando a geólogos y sismólogos la interpretación causal de dichos procesos, como profesionales de la arquitectura y de la geografía urbana nos interesa contrastar en Lorca las repercusiones de los terremotos de 2011 sobre las estructuras arquitectónicas, históricoartísticas y modernas, para extraer experiencias propositivas de futuro, que puedan paliar, en alguna medida, sus efectos catastróficos sobre las personas, el patrimonio edificado y el parque inmobiliario.

\subsection{Sismos de periodos históricos e instrumentales en la zona}

Lorca se ubica en la región Ibero-Mogrebí de riesgo sísmico para estructuras y personas, que ha sufrido múltiples terremotos, constatables a través de los registros sísmicos detectados en el periodo histórico (hasta 1930) e instrumental (a partir de 1930) (Mezcua y Martínez, 1983), de los cuales hemos entresacado el catálogo de sismos y réplicas de mayor intensidad y magnitud ( $>3^{\circ}$ Richter), producidos en la ciudad de Lorca entre 1674 y 2011, que recogemos en la tabla 1.

Tabla 1

CATÁLOGO DE SISMOS EN LORCA. PERIODO HISTÓRICO (1674-1930)

\begin{tabular}{|c|c|c|c|c|c|c|}
\hline Fecha & Hora & Longitud & Latitud & Prof. Km & Magnitud & Intensidad \\
\hline $1579-01-30$ & & $-1,7 \mathrm{O}$ & $37^{\circ} 06^{\prime} \mathrm{N}$ & & & VII \\
\hline $1674-08-10$ & $00-00-00$ & $01^{\circ} 42^{\prime} \mathrm{O}$ & $37^{\circ} 42^{\prime} \mathrm{N}$ & & ---- & VII \\
\hline $1674-08-28$ & $21-30-00$ & $01^{\circ} 42^{\prime} \mathrm{O}$ & $37^{\circ} 42^{\prime} \mathrm{N}$ & & ---- & VIII \\
\hline $1674-08-29$ & $00-00-00$ & $01^{\circ} 42^{\prime} \mathrm{O}$ & $37^{\circ} 42^{\prime} \mathrm{N}$ & & ---- & VII \\
\hline $1755-11-01$ & $09-40-00$ & $01^{\circ} 42^{\prime} \mathrm{O}$ & $37^{\circ} 42^{\prime} \mathrm{N}$ & & & \\
\hline $1818-12-20$ & $09-45-00$ & $01^{\circ} 42^{\prime} \mathrm{O}$ & $37^{\circ} 42^{\prime} \mathrm{N}$ & & ---- & VI / VII \\
\hline $1862-01-22$ & $09-00-00$ & $01^{\circ} 42^{\prime} \mathrm{O}$ & $37^{\circ} 42^{\prime} \mathrm{N}$ & & --- & ---- \\
\hline
\end{tabular}

Fuentes: Cabañas, L. et al. Informe sobre el sismo de Lorca... 2011. / Mezcua, J. y Martínez, J. M. Sismicidad del área Ibero-Mogrebí. 1983. Elaboración propia.

El terremoto del 30 de enero de 1579 produjo en Lorca la espantada del vecindario con sus efectos sobre «las casas y edificios muy a peligro y arruinadas y muchas dellas caydas...», presuntamente un 70 \% (Martínez y Fernández, 1986).

El 28 de agosto de 1674 se produjo un terremoto en Lorca, de $6^{\circ}$ Richter $^{5}$, al que siguieron réplicas por espacio de un mes. Su intensidad produjo daños considerables en estructuras ordinarias, bien construidas, y severos en las más deficientes. Destruyó un $30 \%$ del caserío lorquino (Mezcua y Martínez, 1983).

El macrosismo de Lisboa, de 1 de noviembre de $\mathbf{1 7 5 5}$, por la acción combinada de terremoto, tsunami e incendio produjo 60.000 muertos en la capital lisboeta y destrozos patrimoniales impagables (Sousa, 1928), afectando a las costas de Huelva y Cádiz.

No debe olvidarse que el mayor riesgo sísmico de la fachada atlántica peninsular no es por terremoto, sino por maremoto (Campos, 1991a). Es seguro que el fenómeno volverá a repetirse, puesto que ha quedado registrado, al menos, en los años 1755, 1531, 949, 881

5 De intensidad VIII (Destructivo) en la escala de Mercalli (que evalúa la intensidad de los terremotos, a través de los efectos y daños causados en las estructuras edificadas). 
y 395 de nuestra era, según recientes investigaciones. Contra el fenómeno de maremotos cabe la alerta temprana (Campos, 1991b), puesto que desde que se produjera el fenómeno, a $600 \mathrm{Km}$ de distancia de la costa, hasta la llegada de las olas a la misma, mediarían al menos 20 minutos, fundamentales para la evacuación, siempre que se alertara oportunamente a la población.

En Lorca también tuvo repercusiones el macro-sismo de Lisboa, del 1 de noviembre de 1755. Da cuenta de él, dieciocho días después, Monseñor Thomás Yeri Villarroel, Obispo de Cartagena: "Que en dicho día, a hora de las diez y cuarto de la mañana, se sintió dicho fenómeno que duró nueve o diez minutos, causando grande pavor generalmente (pero bendito Dios) no se ha experimentado en esta jurisdicción desgracia alguna en sus individuos, ni en irracionales, edificios, ni campos. Solo en el convento de Nuestra Señora de las Mercedes, redención de cautivos de esta ciudad, se reconoció haberse quebrantado la bóveda del coro, de donde cayeron algunos ladrillos. Y también se quebró la pared fuerte

Tabla 2

CATÁLOGO DE SISMOS EN LORCA. PERIODO INSTRUMENTAL (1930-2011)

\begin{tabular}{|c|c|c|c|c|c|c|}
\hline Fecha & Hora & Longitud & Latitud & Prof. Km & Magnitud & Intensidad \\
\hline 1932-04-04 & $09-53-00$ & $01^{\circ} 42^{\prime} \mathrm{O}$ & $37^{\circ} 40^{\prime} \mathrm{N}$ & & ---- & V \\
\hline 1932-08-31 & $07-34-47$ & $01^{\circ} 42^{\prime} \mathrm{O}$ & $37^{\circ} 40^{\prime} \mathrm{N}$ & & 3,5 & IV \\
\hline 1963-05-30 & $01-54-49$ & $01^{\circ} 53^{\prime} \mathrm{O}$ & $37^{\circ} 46^{\prime} \mathrm{N}$ & 5 & 4,0 & $\mathrm{~V}$ \\
\hline 1964-03-20 & $06-39-41$ & $01^{\circ} 42^{\prime} \mathrm{O}$ & $37^{\circ} 41^{\prime} \mathrm{N}$ & -- & ---- & III \\
\hline $1974-02-26$ & $10-23-40$ & $01^{\circ} 51^{\prime} \mathrm{O}$ & $37^{\circ} 41^{\prime} \mathrm{N}$ & 8 & 3,3 & ---- \\
\hline 1975-01-18 & $11-43-50$ & $01^{\circ} 42^{\prime} \mathrm{O}$ & $37^{\circ} 40^{\prime} \mathrm{N}$ & -- & ---- & III \\
\hline $1975-08-27$ & $05-58-13$ & $01^{\circ} 51^{\prime} \mathrm{O}$ & $37^{\circ} 43^{\prime} \mathrm{N}$ & 5 & 3,1 & ---- \\
\hline 1977-06-06 & $10-49-12$ & $01^{\circ} 43^{\prime} \mathrm{O}$ & $37^{\circ} 38^{\prime} \mathrm{N}$ & 9 & 4,2 & VI \\
\hline 1977-06-06 & $16-01-00$ & $01^{\circ} 48^{\prime} \mathrm{O}$ & $37^{\circ} 39^{\prime} \mathrm{N}$ & 8 & 3,9 & IV \\
\hline 1977-06-07 & $04-32-57$ & $01^{\circ} 52^{\prime} \mathrm{O}$ & $37^{\circ} 39^{\prime} \mathrm{N}$ & 8 & 3,6 & ---- \\
\hline $1977-06-07$ & $07-54-41$ & $01^{\circ} 49^{\prime} \mathrm{O}$ & $37^{\circ} 39^{\prime} \mathrm{N}$ & 9 & 3,2 & III \\
\hline 1977-06-09 & $08-17-22$ & $01^{\circ} 48^{\prime} \mathrm{O}$ & $37^{\circ} 39^{\prime} \mathrm{N}$ & 6 & 3,5 & ---- \\
\hline 1977-06-09 & $11-10-47$ & $01^{\circ} 47^{\prime} \mathrm{O}$ & $37^{\circ} 39^{\prime} \mathrm{N}$ & 8 & 3,1 & ---- \\
\hline 1977-06-21 & 08-00-14 & $01^{\circ} 41^{\prime} \mathrm{O}$ & $37^{\circ} 42^{\prime} \mathrm{N}$ & 5 & 3,3 & ---- \\
\hline 1977-07-05 & $13-40-43$ & $01^{\circ} 42^{\prime} \mathrm{O}$ & $37^{\circ} 42^{\prime} \mathrm{N}$ & -- & 3,0 & --- \\
\hline 1978-03-24 & $13-01-24$ & $01^{\circ} 42^{\prime} \mathrm{O}$ & $37^{\circ} 38^{\prime} \mathrm{N}$ & 5 & 4,3 & ---- \\
\hline 1979-02-16 & 05-04-15 & $01^{\circ} 52^{\prime} \mathrm{O}$ & $37^{\circ} 40^{\prime} \mathrm{N}$ & -- & 2,9 & III \\
\hline $2011-05-11$ & $15-05-13$ & $01^{\circ} 40^{\prime} \mathrm{O}$ & $37^{\circ} 42^{\prime} \mathrm{N}$ & 2 & 4,5 & VI \\
\hline $2011-05-11$ & $16-47-25$ & $01^{\circ} 40^{\prime} \mathrm{O}$ & $37^{\circ} 41^{\prime} \mathrm{N}$ & 3 & 5,1 & VII \\
\hline 2011-05-11 & $20-37-45$ & $01^{\circ} 39^{\prime} \mathrm{O}$ & $37^{\circ} 41^{\prime} \mathrm{N}$ & 4 & 3,9 & IV \\
\hline
\end{tabular}

Fuentes: Mezcua, J. y Martínez, J. M. Sismicidad del área Ibero-Mogrebí. 1983. IGN. Elaboración propia. 
de los pies de la Iglesia de el dicho convento. Y en el de Nuestra Señora de la Consolación, religiosas Mercedarias haberse desplomado una pared del patio. Y en el Nuestro Señor Padre San Francisco quebrantándose los arcos torales de la Capilla mayor y presbiterio, como también la pared toral de dicha capilla, por el costado que mira al Norte. Y aunque se siguieron algunos otros terremotos sensibles fueron de muy corta duración, sin que en unos ni otros haya habido casas quebradas, ni haya podido inquirirse hayan antecedido señales que lo anunciasen». (Martínez, 2001: 403).

El 20 de diciembre de 1818, a las 9:45 horas, se produjo un sismo en Lorca, que se sintió también en Totana y Murcia, con intensidad entre VI y VII (Mercalli), con efectos de personas heridas entre los escombros de las edificaciones y hundimiento de tierras.

A partir de 1930, la serie sísmica se inserta en el periodo instrumental, que los sismólogos consideran así cuando el terremoto ha sido registrado instrumentalmente al menos por tres estaciones y con coordenadas epicentrales calculadas, por métodos gráficos o numéricos, como se recoge en la tabla 2.

\subsection{El sismo de Lorca de 2011, comparado con otros terremotos}

Fueron dos terremotos, uno premonitorio (de magnitud $4,5^{\circ}$ Richter) y otro principal (de $5,1^{\circ}$ Richter), ocurridos el 11 de mayo de $\mathbf{2 0 1 1}$, con epicentro a $2 \mathrm{~km}$ al NE de la ciudad de Lorca, a una profundidad entre 2 y $3 \mathrm{~km}$, y aceleración sísmica de $037 \mathrm{~g}$ horizontal $^{6}$ y 131 réplicas, los que produjeron el catastrófico balance de nueve muertos, 293 heridos y enormes daños arquitectónicos.

Los mayores destrozos no se debieron tanto a la magnitud de $5,1^{\circ}$, como a la conjunción de varios efectos en cadena: la escasa profundidad del hipocentro en la corteza terrestre, lo que provocó ondas sísmicas de período muy corto; la aceleración tres veces superior a la normal, y la mayor amplificación de las ondas, al transmitirse por terrenos aluviales.

Se le suele dar mucha importancia a la magnitud del terremoto (expresada en escala Richter) y no tanto a la intensidad, en la que influye decisivamente la posición del hipocentro que lo provoca (punto exacto en la fractura que produce el sismo) y su cercanía a núcleos habitados ${ }^{7}$.

Se debe a que, en el estudio de los terremotos por la Geología, los más importantes son aquellos que se producen en las denominadas zonas de subducción (terremotos de placas terrestres, o macrosismos) y se consideran de menor importancia, y de menor interés, los terremotos de fallas activas (que son de segundo orden), despreciables en su magnitud frente a los primeros en un análisis tectónico. Sin embargo, como se ha comprobado en Lorca y en Albolote, en la Península, alejada de zonas de subducción, los terremotos de fallas activas son mucho más importantes desde el punto de vista geotécnico, es decir, de la Geología aplicada a la construcción, porque dada su cercanía a núcleos de población, tienen una mayor repercusión por los daños catastróficos reales que pueden provocar.

Para una magnitud determinada, los daños a las poblaciones dependen tanto de la distancia al núcleo urbano (en el caso de Lorca, el terremoto sucedió en la misma periferia del núcleo), como de la profundidad del hipocentro (en el caso de Lorca, al tratarse de una falla, estaba muy superficial). Por eso, los daños registrados ponen de manifiesto que el terremoto

6 El dato de la aceleración sísmica registrada en Lorca, que es el que determina la ACCIÓN A LOS EDIFICIOS, con el que se calculan las estructuras, fue más del triple de la prevista en el mapa geológico de riesgo sísmico de la norma sismorresistente vigente (NCSE-02).

7 El último terremoto con una intensidad similar en España se produjo al NE del núcleo de Aledo (Murcia), el 29 de enero de 2005, pero al ocurrir lejos de la zona habitada, no tuvo las mismas trascendencias sociales y económicas que el de Lorca (Cabañas et al., 2011: 29). 
ha sido mucho más importante (desde el punto de vista constructivo, no geológico) de lo que inicialmente se creyó, atendiendo sólo a su magnitud $5,1^{\circ}$ Richter.

Este terremoto no es comparable con el episodio reciente de Japón (central nuclear de Fukushima), del 11 de marzo de 2011, que fue un fenómeno sísmico producido por el rozamiento de placas tectónicas terrestres en una zona de subducción de gran actividad. En el caso del terremoto de Lorca, no se trata de una zona de subducción, sino de fallas activas que registran un muy leve movimiento de ruptura (terremoto de fallas), pero que, por desgracia, se encuentran situadas bajo el mismo núcleo urbano y de ahí su repercusión en las construcciones.

En el momento actual del estado de la ciencia, es imposible predecir un terremoto. Lo que sí puede hacerse es definir y estudiar mejor las zonas de mayor riesgo sísmico, porque, en el caso de Lorca, aunque el terremoto haya ocurrido en una de las tres zonas de mayor riesgo sísmico de la Península (previstas en la norma NCSE-02), su intensidad ha sido más del triple de la prevista, según los datos registrados de aceleración (Cabañas, 2011) y (Roldán, 2011).

\subsection{Experiencias sísmicas en otras ciudades patrimoniales}

Resulta necesario valorar los efectos de los sismos históricos sobre otras arquitecturas patrimoniales, ya que están realizadas con estructuras resistentes de similares materiales y sistema estructural, a base de muros, entramados, bóvedas, etc, para importar experiencias del comportamiento real de estos edificios, intensamente sometidos a la acción sísmica, como por ejemplo los que construyeron los españoles en Iberoamérica con las mismas técnicas, o el patrimonio monumental de la península italiana:

- En Puebla, ciudad mexicana, el 15 de junio de 1999, a las 15:41'06", hora local, se produjo un sismo de escala $6,7^{\circ}$ Richter, con epicentro a profundidad de $90 \mathrm{~km}$. Produjo 16 muertos y afectó al Centro Histórico (Patrimonio Mundial) con derrumbe del $70 \%$ del Palacio Municipal (XVII), fractura de una de las torres de la Compañía de Jesús y daños en los templos de San Agustín, San Roque, San Francisco y la Virgen de los Remedios. Destruyó 120 inmuebles, la mayor parte coloniales, y un $30 \%$ de edificios no coloniales sufrieron daños en el $70 \%$ de sus estructuras. La cuantía de los daños se valoró en 150 millones de dólares.

- En Morelia, ciudad mexicana del Patrimonio Mundial, como en todo el sector central y meridional de México, de alto riesgo sísmico, el Departamento de Estructuras de Ingeniería Civil de la Universidad de Michoacán, a cargo de Guillermo Martín Ruiz, es pionero en estudios sobre el comportamiento estructural de la vulnerabilidad sísmica de los edificios patrimoniales de Morelia, al objeto de adecuar las técnicas de restauración patrimonial y rehabilitación edificatoria en las torres y naves de la Catedral y edificios aledaños a las experiencias del comportamiento de estructuras y materiales sometidas a movimientos sísmicos.

- En Friuli, el terremoto de mayo de 1976, de 6,5 $5^{\circ}$, produjo 1.000 muertos, 8.800 heridos y 45.000 personas sin techo.

- En Asís, el terremoto de 22 de septiembre de 1997, de 5,8 , destrozó la bóveda de la nave central y el ábside con los frescos del Giotto - 1295 - de la basílica de San Francisco. Tras su restauración, fue declarada Patrimonio Mundial en 2000.

- En L'Àquila, el terremoto de 6 de abril de 2009, 6,7º, produjo 308 muertos, 1.500 heridos y dejó a 50.000 personas sin hogar, junto al destrozo total o parcial de notables elementos patrimoniales de los siglos XIII al XVIII y miles de edificaciones. 
En estas estructuras de fábrica son especialmente vulnerables los puntos más rígidos de las mismas (esquinas y estribos) y determinadas tipologías estructurales, como las torres, los cruceros y cimborrios y, en general, los elementos rígidos y esbeltos, donde se puede producir el colapso total o parcial.

En la actualidad, hay investigadores trabajando para desarrollar una metodología de intervención en edificios de mampostería no reforzada, línea de investigación ya experimentada por distintos centros de investigación italianos, a partir del terremoto de Friuli, que comienza a utilizarse en 1982. El Departamento de Mecánica de Medios Continuos y Teoría de Estructuras de la Universidad de Granada aplica esta metodología a los edificios históricos de esta ciudad española con bienes declarados Patrimonio Mundial en un territorio sísmico de alto riesgo (Arango, 2003).

El Grupo de Investigación de Construcciones Arquitectónicas de la Universidad de Extremadura considera que los métodos modernos de cálculo, basados en hipótesis creadas para materiales estructurales como hormigón y acero, con sistemas de nudos rígidos, no son aplicables a las estructuras de fábrica, con las que están construidos los edificios de arquitectura popular (a pequeña escala) y el patrimonio monumental (a mayor escala), que no son monolíticos, sino formados a partir de piezas pequeñas, cuyo comportamiento es de difícil modelización en ordenador. Este grupo trabaja en el refuerzo y consolidación de las bóvedas con capas estructurales compatibles que les doten de una mayor ductilidad a la acción sísmica.

A ICOMOS (Instituto para la Conservación de Monumentos y Sitios Históricos) de la UNESCO le preocupa la serie de riesgos naturales que afectan a los países mediterráneos, dotados de ingente patrimonio monumental, los destrozos provocados por los terremotos y el establecimiento de normas y metodologías para disminuir la vulnerabilidad, tanto en materia de prevención, como en las obras de rehabilitación a realizar y en la creación de mecanismos de respuesta rápida y eficaz a los desastres. En noviembre de 2008, la UNESCO organizó en Olimpia (Grecia) un taller internacional sobre: «Gestión de Riesgos en Bienes del Patrimonio Mundial».

\section{La importancia del patrimonio histórico-artístico de Lorca}

\subsection{Bienes patrimoniales}

El patrimonio edificado de Lorca se estructura en tres categorías:

- Edificios singulares, civiles y religiosos, de mayor categoría patrimonial (Grados 1 y 2) con declaración o incoación, como Monumentos Nacionales o Bienes de Interés Cultural (B.I.C.).

- Edificios con interés arquitectónico y carácter de vivienda tradicional de los siglos XIX y XX (Grado 3).

- La trama viaria y la escena urbana del Centro Histórico, dignas de protección y conservación, porque conforman el molde urbano diferenciador de Lorca, como ciudad modelo de sí misma y soporte de los restantes elementos arquitectónicos.

El Centro Histórico de Lorca fue declarado Conjunto Histórico-Artístico por Decreto 612/1964, de 5 de marzo (BOE, nº 65 de 16-03-1964), siendo el primero en alcanzar tal reconocimiento en la región de Murcia. Con la Ley 16/1985, de 25 de junio, del Patrimonio Histórico Español (LPHE), el Conjunto Histórico de Lorca pasa a tener la consideración de B.I.C. con categoría de Conjunto Histórico.

El Plan General de Ordenación Urbana (PGOU, 2003) de Lorca recoge el perímetro de declaración del Conjunto Histórico y lo divide en dos sectores: I y II: 
- El SECTOR I comprende el Casco Antiguo, la fortaleza y los barrios altos de la falda del Castillo, de alto valor arqueológico y paisajístico, con caserío consolidado, pero muy deteriorado, que acoge a una población muy vulnerable con problemas de infravivienda, accesibilidad y marginalidad social. Los únicos edificios patrimoniales que aún se mantienen en pie, aunque en ruinas, son las iglesias de las zonas altas de San Pedro, Santa María y San Juan, que dan nombre a los barrios respectivos.

- El SECTOR II, integra el Centro Histórico, propiamente dicho.

\subsection{Figuras de protección}

A los efectos de protección y conservación patrimonial de las distintas unidades que conforman el Conjunto Histórico, la municipalidad ha puesto en marcha desde el año 2000 varias figuras de planeamiento:

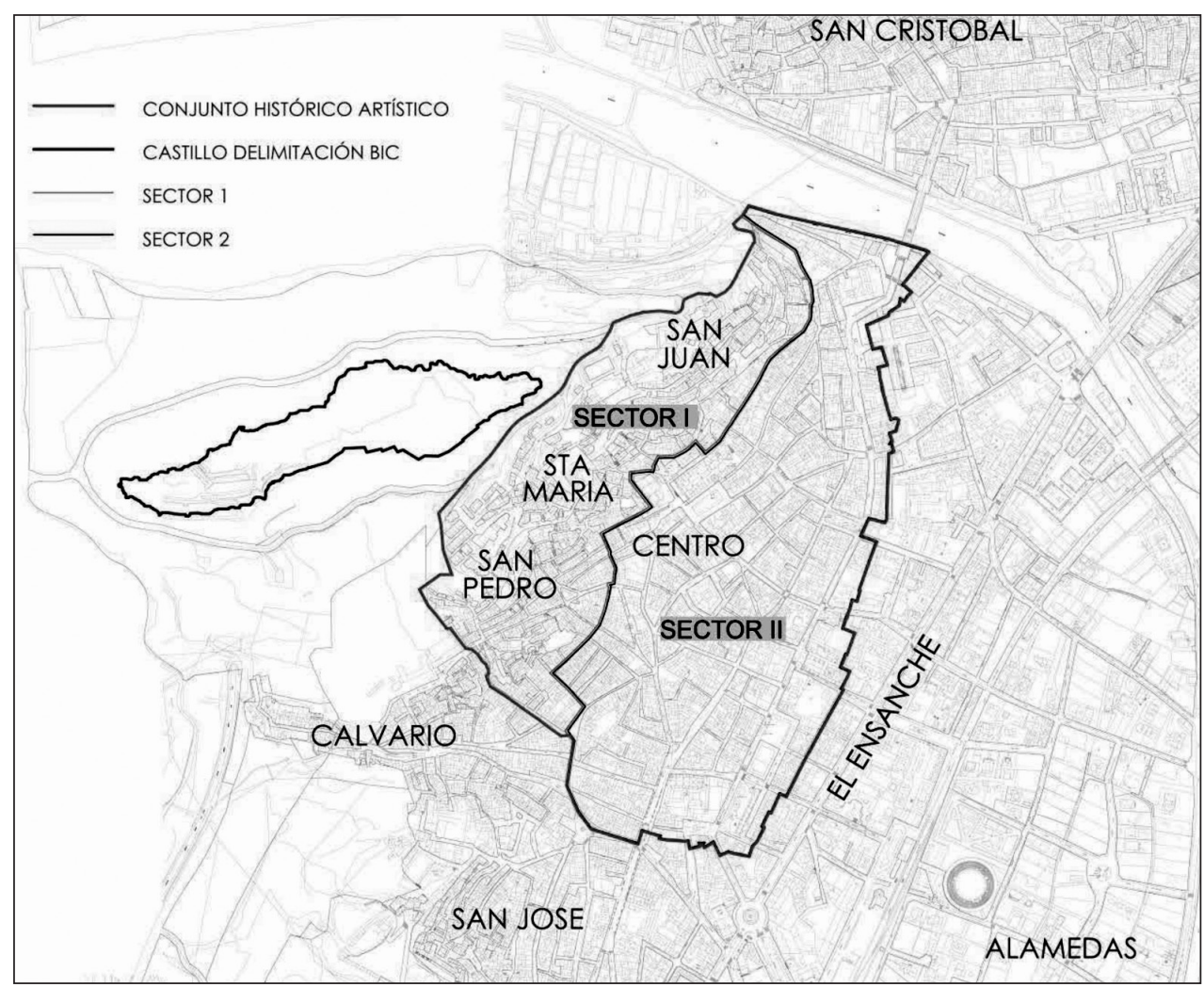

Figura 4. Plano del Plan Director para la Recuperación del Patrimonio Cultural de Lorca. 2011.

\section{Para el SECTOR I:}

- Plan Integral para los Barrios Altos de Lorca (P.I.B.A.L.). Para su regeneración urbana, el Ayuntamiento ha aprobado un plan con los objetivos, directrices y criterios de recuperación física, social económica e infraestructural en un ámbito que abarca los barrios de San Lázaro, Calvario, San Pedro, Santa María, San Juan y 
San Cristóbal. Entre sus objetivos figura la rehabilitación del Patrimonio Cultural en las ruinas de la Iglesia de Santa María, en la Ermita de San Roque, en la Puerta de San Antonio y en los lienzos de la muralla.

- Plan Especial de Protección de la Muralla de Lorca (P.E.P.M.L.). Al objeto de asegurar la adecuada protección y conservación de la Muralla, Antemuralla, lienzos, torres y torreones, el Ayuntamiento encarga en 2004 la redacción del Plan al arquitecto Alfredo Vera Botí y a los arqueólogos Indalecio Pozo Martínez, Alfonso Robles Fernández y Elvira Navarro Santacruz, que obtuvo la aprobación definitiva en febrero de 2006. Se definieron y regularon los distintos tipos de intervenciones en las manzanas donde quedan restos y trazas de la Muralla y sus torreones, en los tramos en que aparece integrada entre edificaciones o como medianera entre propiedades (Vera et al., 2004).

\section{Para el SECTOR II:}

- Plan Especial de Protección de Rehabilitación Integrada (P.E.P.R.I.) del Sector II del Conjunto Histórico de Lorca. Redactado por el arquitecto Simón Ángel Ros Peran, y con aprobación definitiva en mayo de 2000, recoge las directrices y normativas para este sector urbano y procede a la catalogación de los elementos unitarios que conforman el conjunto para la protección, rehabilitación y refuncionalización de espacios urbanos, edificios y elementos de la escena urbana

\section{Daños del terremoto de Lorca}

Se estudian a continuación los daños divididos en cuatro apartados: daños en estructuras de fábrica, de los edificios patrimoniales, que fueron los más afectados; daños en estructuras de edificios nuevos, entendiendo por tales las construidas con hormigón y/o con acero; daños en elementos secundarios de albañilería y los daños personales, resultado de los anteriores.

La clave del sismo de Lorca radica en su elevada intensidad, constatada en los acelerógrafos del IGN (Instituto Geográfico Nacional), instalados en el centro de la población, que registraron $0,37 \mathrm{~g}$, cuando la norma preveía sólo $0,12 \mathrm{~g}$, es decir, la tercera parte (Roldán, 2011). Esto se demuestra con la siguiente explicación:

La aceleración de cálculo «ac» es el resultado de tres factores:

- La aceleración básica $\left(\mathrm{a}_{\mathrm{b}}\right)$ establecida en la norma NCSE-02, que para Lorca es $0,12 \mathrm{~g}$.

- El tipo de terreno (coeficiente $S$ ), que para el terreno blando de Lorca es del orden de 1,30 , considerando un terreno medio tipo III, con $\mathrm{C}=1,60$.

- La probabilidad de que en el período de vida útil de la edificación se supere la aceleración básica (coeficiente r), función del tipo de edificio, que para «normal importancia» como las edificaciones de viviendas, es 1,00. Es decir, que la previsión de la norma de que se superase la aceleración básica $\mathrm{a}_{\mathrm{b}}$ durante la vida útil del edificio (50 años según el actual Código Técnico de la Edificación), es mínima, prácticamente nula.

Por consiguiente, la aceleración previsible según la norma para preparar la respuesta del edificio, es: $\mathbf{0 , 1 2} \mathrm{g} \times \mathbf{1 , 3 0} \times \mathbf{1 , 0 0}=\mathbf{0 , 1 6} \mathrm{g}$

La aceleración registrada $(0,37 \mathrm{~g})$ es 2,31 veces la aceleración de cálculo $(0,16 \mathrm{~g})$ y 3,08 veces la básica $(0,12 \mathrm{~g})$. Es decir, que las acciones recibidas por las edificaciones, a igualdad del resto de parámetros, han sido del orden de más del doble de las previstas por la propia normativa actual, debiendo calificarse la respuesta de las estructuras de los edificios nuevos, por tanto, de «muy buena» ante este valor anormalmente alto de una acción prevista. 
Una semana después del sismo se realizó un chequeo técnico, sobre 6.762 edificios para la evaluación de daños y del grado de habitabilidad. El resultado fue que 5.155 de ellos tenían estructura tradicional y los 1.607 restantes estructura tecnológica $^{8}$. De los 889 edificios afectados (el 13,1\% del total de edificios), 550 presentaban daños estructurales moderados (etiqueta amarilla) y 326 daños estructurales graves (etiqueta roja), a los que se sumaban los 13 edificios demolidos. Las zonas urbanas más afectadas fueron el Centro Histórico (16\% de las edificaciones), el barrio de La Viña (41\%) y la avenida de Santa Clara (el $40 \%$ ). (Cabañas et al., 2011: 116).

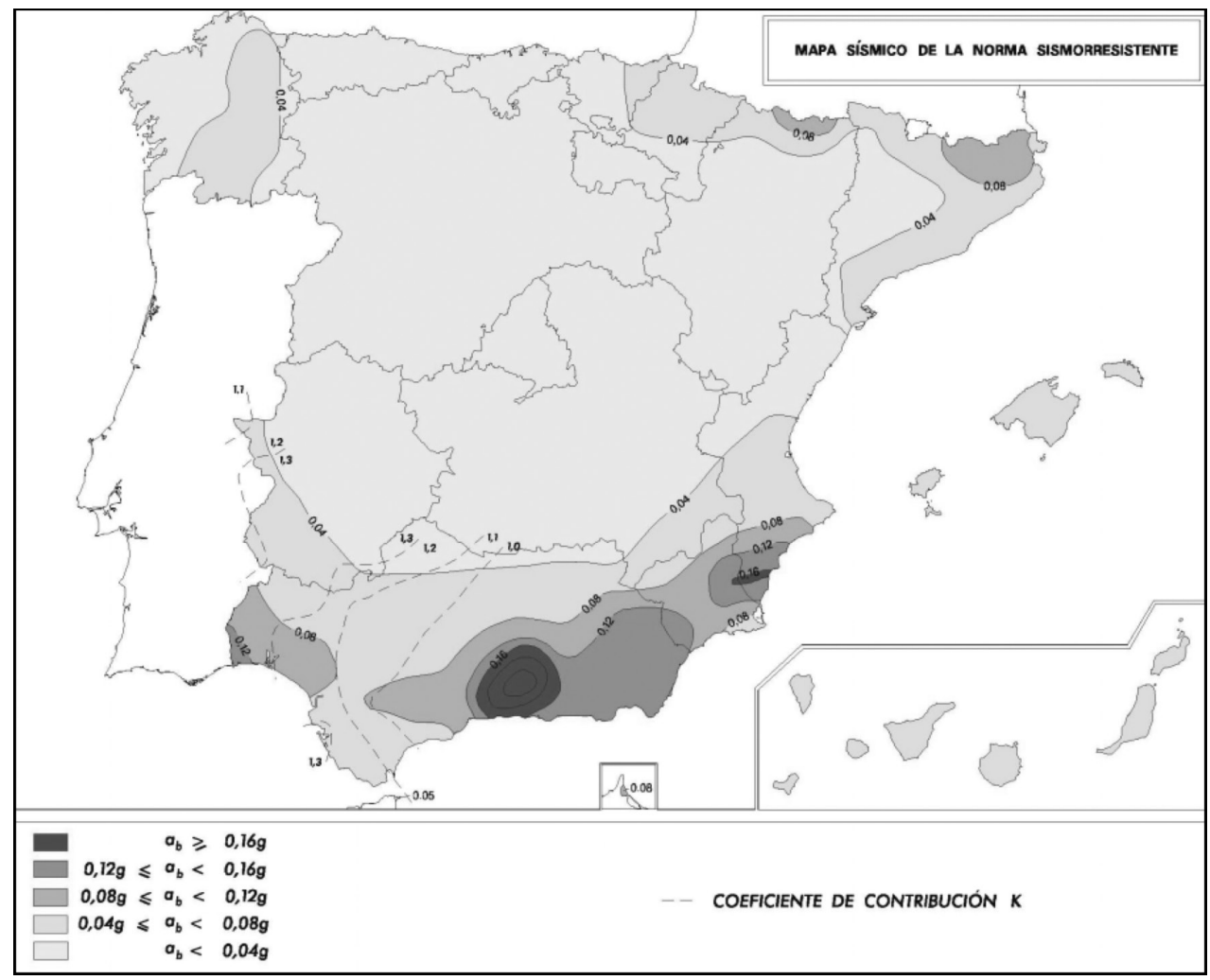

FIGURA 5. Mapa sísmico de la norma sismorresistente vigente (NCSE-02), que indica la aceleración básica $\left(\mathrm{a}_{\mathrm{b}}\right.$ ) y el coeficiente de contribución (k). Obsérvese como el basamento de la Península (la Meseta) es la zona menos afectada y las zona de mayor aceleración pertenecen, en el Sur, a las provincias de Granada $(0,25 \mathrm{~g})$, Murcia $(0,16 \mathrm{~g})$ y Huelva $(0,12 \mathrm{~g})$ y, en los Pirineos, a parte del territorio de Gerona y Huesca (ambas $0,06 \mathrm{~g}$ ).

El Real Decreto Ley, 6/2011, de 13 de mayo, de adopción de medidas urgentes para reparación de los daños ocasionados por el terremoto de Lorca, fijaba el 5 de septiem-

8 En el informe del IGME (Cabañas et al., 2011) se denominan «edificios tecnológicos» a los construidos a base de pórticos de hormigón armado. Se censaban, no obstante, del orden de 1.400 edificios más, catalogados de «estructura tradicional», que tenían muros de carga modernos (de un pie de ladrillo perforado) y forjados de hormigón, por lo que se concluye que existían del orden de 3.000 edificios con estructuras «modernas» de hormigón armado, construidos estando en vigor las normas sísmicas (desde 1968). 
bre de 2011 como fin del plazo establecido para el derribo de viviendas en ruina. Según la concejalía municipal de urbanismo, el número de viviendas demolidas había sido de $1.164^{9}$, además de 45 naves y un número indeterminado de otras construcciones, unas 150 pendientes de derribo. La corporación emitió 260 decretos de derribo (algunos para varias edificaciones), que afectaron a una superficie total demolida de $164.458 \mathrm{~m}^{2}$, por importe de 22 millones de euros, de los que el $50 \%$ correspondieron a gastos de derribo y el resto a otras emergencias de apuntalamiento, desescombro, limpieza, mantenimiento de fachadas, desvío de líneas eléctricas y señalización del grado de riesgo en los edificios (con etiqueta verde, amarilla, roja y negra).

En el Centro Histórico de Lorca decenas de edificios fueron derribados y convertidos en solares, conservando algunas casonas y palacios sus fachadas apuntaladas para evitar desplomes: los números 4, 5 y 15 de la calle del Álamo, en la esquina con Rubira; el número 7 de la calle Santiago y el 3 de la calle Carril de Caldereros, esquina a Lope Gisbert. Asimismo, la Casa de los Guevara, en la esquina de la calle Juan II con la glorieta de San Vicente y la casa del siglo XV, en el encuentro de esta glorieta con la calle Corredera. En ésta se mantiene en pie la fachada de la casa histórica de los Irurita (XVI), catalogada por el Plan Especial con nivel de protección 2, dada su categoría de Bien de Interés Cultural.

El Ayuntamiento de Lorca y la Consejería de Cultura de la Región de Murcia cifran en 1.650 millones de euros el coste de reconstrucción y revitalización socioeconómica del municipio, tras los seísmos del 11 de mayo, que se justifican en la formulación de 63 proyectos para enfrentar la regeneración urbana.

\subsection{Daños en las estructuras de fábrica}

El terremoto produjo afecciones en 33 edificios históricos con daños de muy difícil cuantificación económica, afectando principalmente a lienzos, puertas y torres de muralla, y a iglesias y conventos que sufrieron daños en bóvedas nervadas, cúpulas, cimborrios, arcos, cubiertas, tejadillos, arbotantes y contrafuertes, así como rotaciones y pérdidas de equilibrio en pináculos y elementos decorativos de coronación.

Inestabilidades geotécnicas en la falda Norte del cerro del castillo; muralla (XII-XIV), colapso y desmoronamientos de tramos exteriores; Torre del Espolón, fracturación y desplazamiento de su posición, desmoronándose la tercera parte de su altura y desapareciendo su perfil original; Porche de San Antonio (XIII-XIV): deriva de un muro de carga y fracturas en el almenado; Colegiata de San Patricio, derrumbe de pináculos y capitales de piedra caliza.

Las 13 iglesias parroquiales de Lorca presentan daños estructurales de gravedad y situación de ruina, que obligaron a su cierre: Santiago (XVIII), cúpula, crucero y coro derrumbados, afectando también a un edificio colindante (Véanse fotografías); San Francisco (XVII), cúpula seriamente dañada; Carmen (XVIII), cúpula muy dañada; San Diego, campanario fracturado y desplazado; Santo Domingo, cúpula que giró sobre sí misma, destrozando los frescos; San Mateo, parte de la fachada desprendida sobre el atrio; Nuestra Señora del Rosario, desplazamiento lateral de la cúpula tras ser seccionada; San Pedro de las Huertas, daños en el techo; Ermita de San Clemente; Monasterio de Clarisas (XVII), derrumbe de muros, y Convento de la Virgen de las Huertas (XVII).

9 Téngase en cuenta, no obstante, que el elevado número de viviendas declaradas en ruina y demolidas, no sólo tiene que ver con los daños causados por el terremoto, sino con el valor y estado previo de las edificaciones (y el rescate del solar). Así, por ejemplo, en edificios de escaso valor, infrautilizados, en desuso, etc, el coste de reparación de los daños del sismo no era compatible con el valor de la construcción, por lo que la decisión en muchos casos fue la demolición. 
De los edificios públicos se vieron afectados, en mayor o menor medida los siguientes: Instituto Ros Giner, construido en 1972 y demolido por los daños estructurales; Instituto Ramón Arcas Meca, se plantea su derribo; Conservatorio de Música Narciso Yepes, en la calle Abada de los Arcos, habilitado en el antiguo Colegio de la Purísima; Estación de ferrocarril de Lorca-Sutullena, derribada por seguridad; Comisaría del Cuerpo Nacional de Policía, y Casa Cuartel de la Guardia Civil y viviendas: demolidas por la gravedad de los daños.

Sin duda, es una catástrofe patrimonial muy importante en sí misma, que, además, anula todas las intervenciones de rehabilitación en edificios históricos de los últimos veinticinco años, con inversiones cuantiosas, como las del Palacio Huerto Ruano o el Pórtico de San Antonio (2007). En 2008 el Consejo de Europa distinguió a Lorca con el Diploma de Honor de los Premios Europa.

\subsubsection{Diagnóstico de daños}

El movimiento de la corteza terrestre, originado por el terremoto, provoca ondas sísmicas que se transmiten fundamentalmente en horizontal hasta la cimentación de los edificios, produciendo sobre su estructura una aceleración denominada «aceleración sísmica». Los edificios tradicionales, a base de muros de fábrica de gran masa, fueron concebidos sólo para aguantar los pesos (fuerzas de la gravedad), pero no para los empujes (horizontales) de un sismo.

En general, cuanto más pesado es un edificio, peor se comporta, como describe la segunda ley de Newton (fuerza = masa x aceleración). En general, también, cuanto más rígido es un edificio, peor se comporta, porque al no ser capaz de admitir la deformación que le impone el sismo, se parten sus puntos rígidos, pudiendo llegar a colapsar. Por eso, dos cualidades (masa y rigidez) en principio buenas para estructuras sometidas a peso, son pésimas para el comportamiento a sismo. Éste es, básicamente, el problema de las estructuras de fábrica.

Dentro del tipo estructural (de muros) influye también su composición de materiales y su aparejo; hay fábricas que resisten más a cortante y que tienen un mejor comportamiento a sismo (las mejor aparejadas). Como apunta el arquitecto Jerónimo Granados, natural de Lorca, profesor de Proyectos Arquitectónicos de la Universidad Católica San Antonio de Murcia, con experiencia en intervenciones de conservación y reconstrucción del patrimonio histórico de Lorca, la gran mayoría de los edificios históricos de la ciudad, de los siglos XVII y XVIII, no está construida con bloques de piedra, como otros monumentos del Norte de España, sino de mampostería de piedra de relleno ${ }^{10}$ y cal, lo que produce fracturas y fisuras de muros por todo el edificio.

Hay otros factores que empeoran el comportamiento de los edificios antiguos, las reformas inadecuadas, empleando masas de hormigón, que alteran la estructura original y provocan comportamientos anómalos ante un sismo. Mientras las intervenciones realizadas a partir de los años 90 han funcionado, en general correctamente, las de los años 70 y 80 , que introdujeron elementos estructurales rígidos de hormigón, tales como forjados, son las que han registrado más y mayores daños estructurales. Por ejemplo, obras realizadas en los años 60, como las de la Torre del Espolón del Castillo o el Porche de San Antonio han magnificado los efectos del sismo por el empleo generalizado de elementos de albañilería y de hormigón de gran peso en sus reformas.

10 Lo mismo ocurrió en el terremoto de Albolote (1956) donde las fábricas de los muros eran en su mayor parte de tapial (fábrica de tierra). 
Los edificios de arquitectura civil del Conjunto Histórico con organización estructural de muros-diafragma en las dos direcciones o con una compleja compartimentación de elementos estructurales y no estructurales han sido menos vulnerables que los edificios de arquitectura religiosa. Sin embargo, los múltiples daños son testigos de la heterogeneidad de sus fábricas, por la falta de enjarjes o por la discontinuidad de los elementos constructivos, en muchos casos producidos por reformas inadecuadas que han desequilibrado el esqueleto de las construcciones. Los núcleos de escalera, que en ocasiones conforman remates singulares, emergiendo de las cubiertas y que constituyen puntos de discontinuidad estructural, se han visto especialmente afectados.

\subsubsection{Tipología de daños}

El fenómeno más fácil de explicar es el vuelco de elementos, que se ha producido en muros no arriostrados, como los lienzos de muralla (en el ala Norte del Castillo). El empuje horizontal del sismo, magnificado en la coronación de estos edificios esbeltos, es capaz de desequilibrar el propio peso del elemento, que cae sin más como un sólido rígido. Un segundo ejemplo de este tipo es el muro de la planta alta de la Estación de ferrocarril, que perdió el equilibrio y cayó sobre la marquesina, destruyéndola a su vez.

Los muros arriostrados (unidos perpendicularmente a otros que los estabilizan) se han fracturado en muchos casos por la rigidez de las esquinas. Los lienzos o paños planos de muro son capaces de vibrar y absorben con esta deformación la energía recibida del sismo, pero las esquinas y contrafuertes no, por lo que, como no tengan en estos puntos una suficiente resistencia a cortante (por tener mampostería de mala calidad, fallos de aparejo, existencia de huecos, obras que los han debilitado o daños anteriores) se parten en estas zonas. A este tipo pertenecen multitud de fracturas localizadas en todo el patrimonio de Lorca.

Las fracturas en las bóvedas son tan variables como el tipo de bóveda y su forma de funcionamiento. En general, las bóvedas fallan debido a los muros. Si los muros que las soportan pierden el plomo (la verticalidad) por el sismo, obligan a las bóvedas a «abrirse» y dejan de trabajar a compresión (la ley que las sostiene), con lo que fallan sistemáticamente, pudiendo llegar a fisurarse o a fracturarse, en gajos o en anillos, según el tipo de bóveda.

Un segundo tipo de fracturación en bóvedas (alternativa o simultánea con la anterior) se produce en las bóvedas más rígidas. Al ser menos flexibles, estar en altura, y mucho más si han sido cargadas con hormigón en obras desafortunadas de intervención, absorben tanta energía del sismo, que puede llegar a romperlas, o a desplazarlas de su base. En el momento en el que una parte importante de la bóveda deje de trabajar a compresión, el sistema estructural pierde el equilibro, llegando a colapsar, como le ha ocurrido a las bóvedas del crucero completo de la iglesia de Santiago. Véanse fotografías.

El problema de las torres es su esbeltez, es decir, la elevada altura que tienen en relación a su base. Al ser muy rígidas y absorber mucha energía del sismo, son obligadas a descuadrarse y su fábrica es sometida a unos esfuerzos (denominados «de cortante») para los que no fueron calculados. Aquellos puntos más rígidos, como las esquinas (Porche de San Antonio) o debilitados por la existencia de huecos, son los que han fallado (caso de las torres-campanario de casi todas las iglesias, como Santiago, Paso Azul o las Clarisas). Véanse fotografías. 

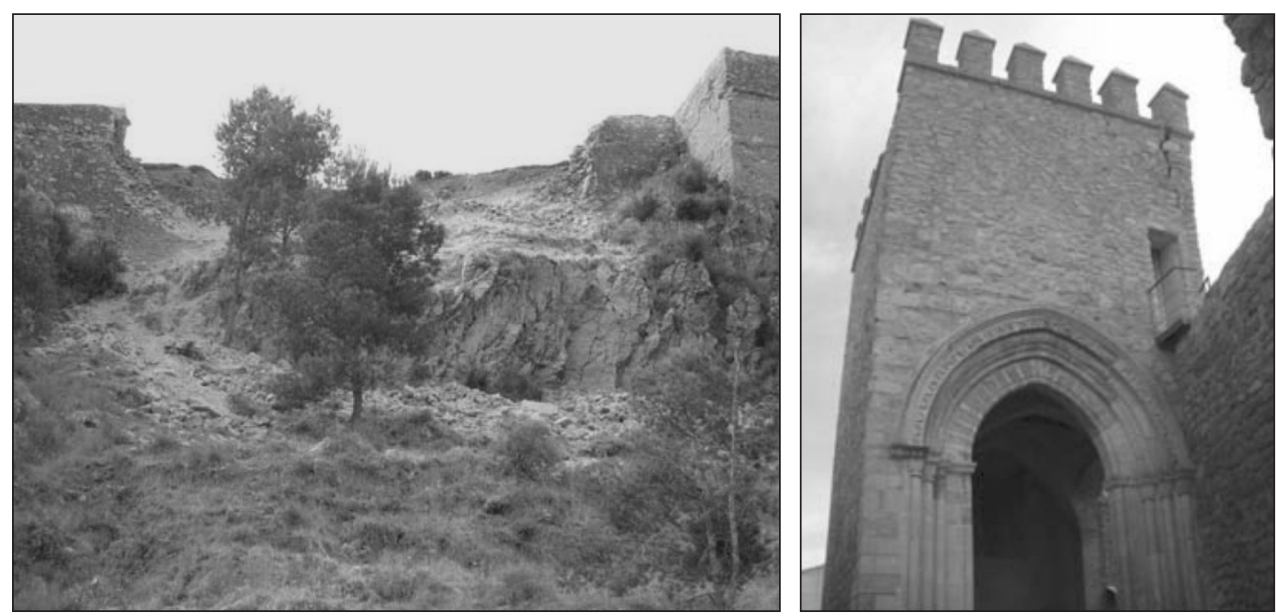

Daños en fortificaciones, a base de elementos masivos de mampostería. A la izquierda (FIGURA 6), lienzo derrumbado de la muralla exterior del Castillo, en la falda Norte. A la derecha (FIGURA 7), torre del Porche de San Antonio, con fractura en una esquina y desaplomado de los muros.
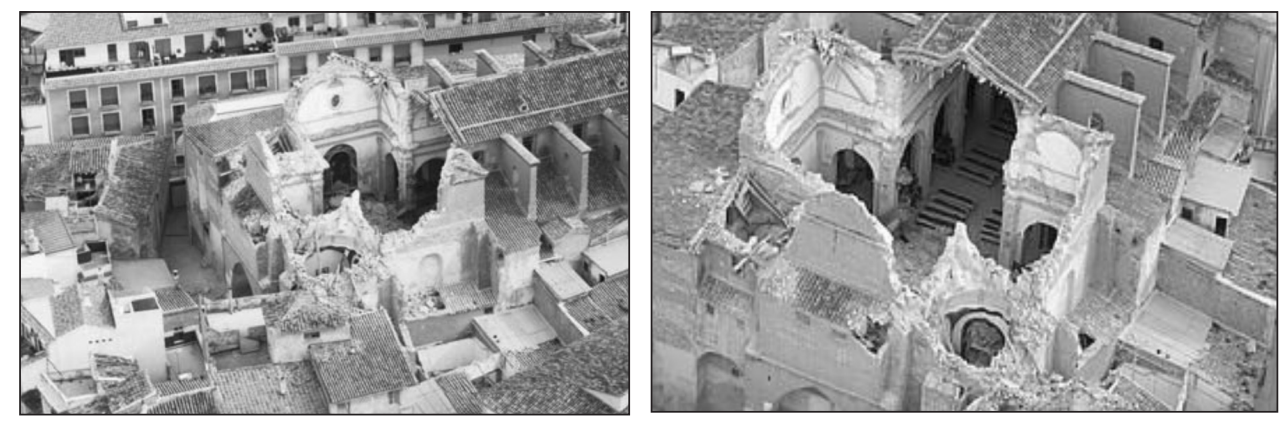

Figuras 8 y 9: Iglesia de Santiago cuyo crucero resultó completamente derrumbado por el sismo. Imágenes aéreas tras el terremoto.
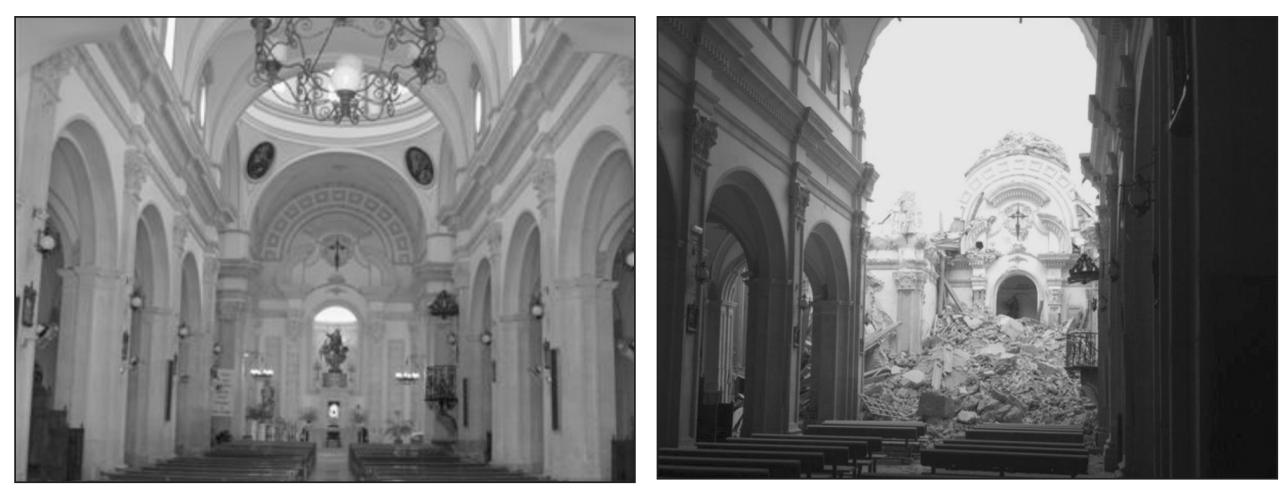

FIgURAS 10 y 11: Iglesia de Santiago fotografiada antes y después del terremoto. Se hundió la parte más rígida de la estructura de cubierta: el crucero con el cimborrio. 
Otro fenómeno que se produce en las torres y en general en todos los puntos elevados de los edificios de fábrica, es el vuelco de los elementos decorativos de coronación (almenas, cornisas, adornos de campanarios, pináculos). Consiste en la pérdida del equilibrio producido cuando el empuje del sismo es tan grande que supera el contrarresto del peso propio de estos elementos. Unas veces se han caído (caso de una torre que fue filmada en directo por un equipo de televisión) y otras veces se ha producido el giro o «baile» de estos elementos, como los pináculos de la iglesia de San Patricio.
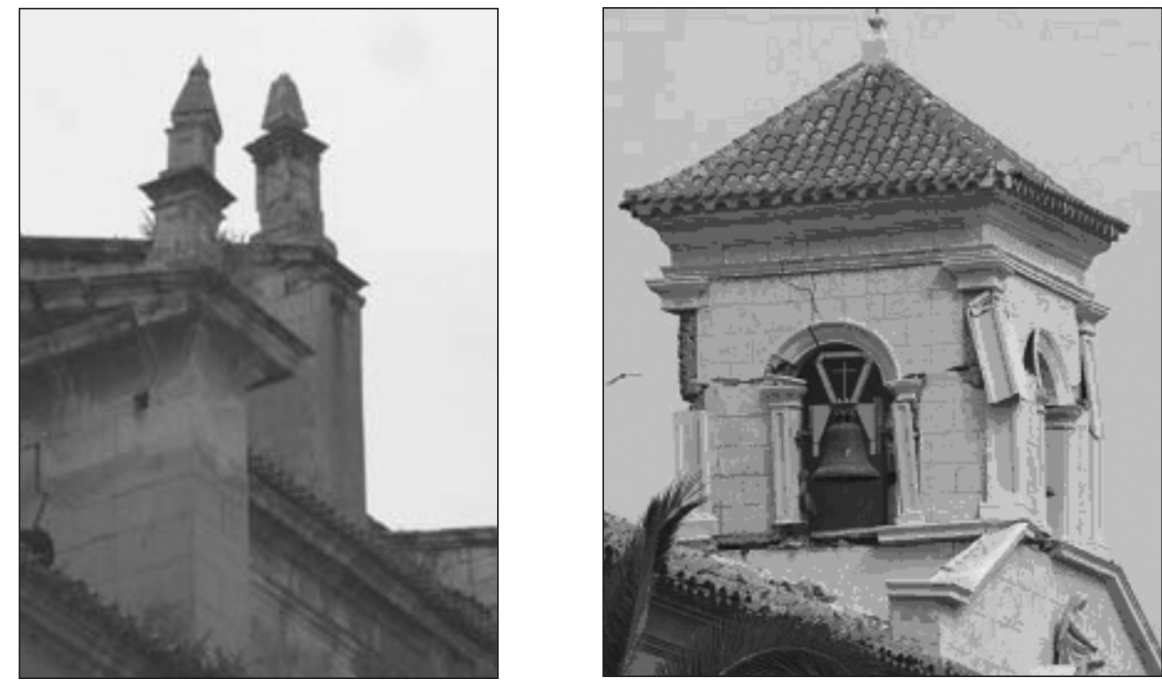

FIGURAS 12 y 13: A la izquierda, elementos de remate de coronación (pináculos) de la iglesia de San Patricio, que han registrado giros e incluso derrumbes, por pérdida de equilibrio ante la acción horizontal de sismo. A la derecha torre-campanario del convento de las Clarisas, fracturado por las zonas del menor resistencia a cortante de la fábrica.
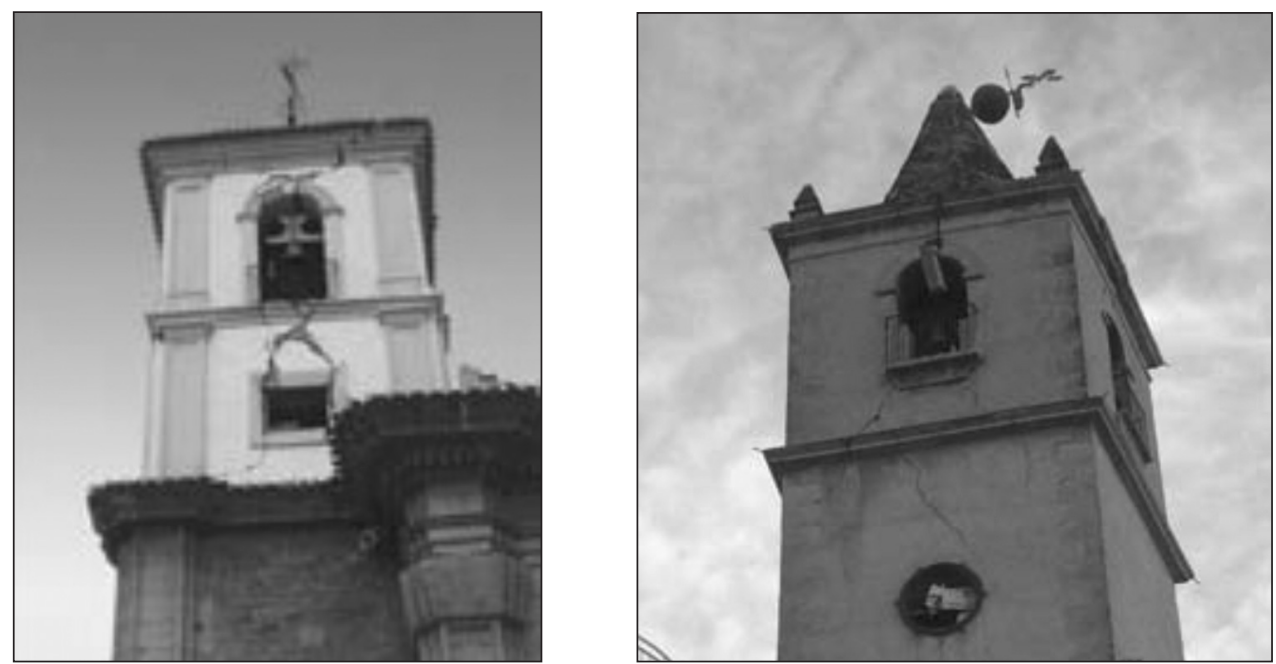

FIgURAS 14 y 15: Torre de la iglesia de Santiago y torre de la iglesia del Paso Azul, con daños por esfuerzo cortante en las fábricas, en las zonas más débiles (de huecos). 

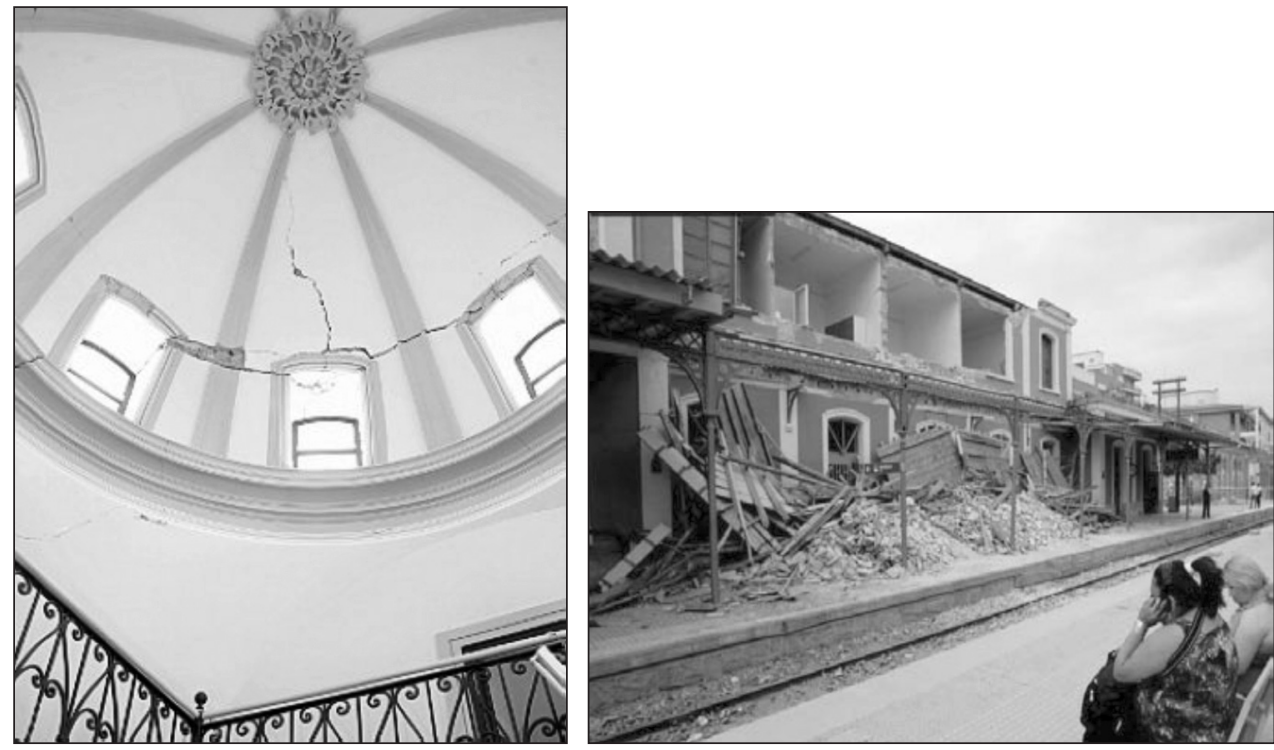

FIgURAs 16 y 17: A la izquierda, cúpula del Conservatorio, fracturada. A la derecha, derrumbe producido en la Estación, en la que el muro de fábrica de ladrillo perdió el equilibrio y cayó sobre la marquesina, rompiendo el entramado de viguetas.

\subsection{Daños en las estructuras modernas}

Los daños en los edificios nuevos, de estructuras porticadas de hormigón armado, se producen en general en la planta baja (por ser la planta que menos posibilidades tiene de absorber, mediante deformación, la energía del sismo), mientras que las afecciones de las estructuras históricas son de muy distinta naturaleza, porque influyen las diferentes organizaciones estructurales, su altura y rigidez, su grado de mantenimiento, las reformas sufridas e incluso el grado de afección por terremotos anteriores en Lorca.

Es muy importante destacar que sólo se han producido dos casos de colapsos de estructuras en edificios nuevos, construidos estando en vigor las normas sísmicas (un edificio colapsó por completo en el momento del sismo y otro se derrumbó unos días después, ante una mínima acción de las máquinas), y todo ello, pese a que la intensidad del terremoto ha sido más del triple de la prevista en el mapa de riesgo sísmico.

Transcurrido un tiempo prudencial desde el terremoto, que ha permitido el análisis de los daños estructurales en los edificios nuevos, ya es posible realizar un diagnostico para extraer conclusiones:

La estructura tipo de «edificio nuevo» (en Lorca y en general, en la mayor parte de España) está realizada con hormigón armado, a base de cimentación directa por zapatas, con atado de cimientos, como mínimo en el perímetro, con muros de sótano, pilares, vigas planas y forjados unidireccionales. Hay casos de edificios con forjado reticular o con losas.

Los daños de las estructuras se han producido en los nudos de las plantas bajas (primer forjado sobre el terreno) y en ellos siempre, independientemente de otros problemas, se han detectado defectos de armado de los pilares (normalmente falta de cercos en las cabezas de los pilares). La actual instrucción (EHE-08) ya preveía este fenómeno y obligaba al 
refuerzo de los cercos de los pilares de hormigón en las zonas sísmicas y a la prolongación del anclaje de las armaduras. También la norma NCSE-02.

Existen elementos estructurales que han fallado en muchos casos, son los «pilares cortos» o «enanos» (Feriche et al, 2011), que emergen de los muros de sótano hasta el primer forjado. Este tipo de pilar, de poca esbeltez, resulta extremadamente rígido y recibe mucha acción sísmica, que lo cizalla (véanse fotografías). Se trata de un elemento fácilmente prescindible, haciendo llegar simplemente el muro de sótano al primer forjado, por lo que el fallo podría calificarse de «absurdo», aunque bien es cierto que no existían experiencias previas reales que constataran tan mal comportamiento sísmico.

Estudio especial merece el único edificio nuevo, cuya estructura fue colapsada por el sismo, situado en la calle Infante Juan Manuel $n^{\circ} 5$, de tres plantas de altura:

- Es la primera vez que se ha visto en España un edificio derrumbado con «forjados apilados», que sí se había experimentado en otras partes del mundo en estos casos (Japón, Perú, Chile, Haití, Italia, Turquía...). Este tipo de colapso es el que genera miles de muertos en otros países, cuando las estructuras colapsan atrapando a las personas dentro. Influye en la siniestralidad tanto la aceleración sísmica como la calidad de las construcciones.

- Se sabe que el derrumbe se produjo al fallar completamente los «pilares cortos» de la planta baja, perdiendo el equilibrio el bloque completo del edificio que, al chocar contra el suelo de la calle, rompió los pilares de todas las plantas por la base y por la cabeza, apilándose los forjados como muestran las fotografías.

- Otro edificio, al otro lado de la calle, con la misma constitución estructural, registró daños en las cabezas de los pilares cortos de la planta baja, pero no colapsó, demostrando lo errático del fenómeno sísmico.

La falta de juntas estructurales también ha producido daños. Cuando se construye una junta estructural, por ejemplo entre dos edificios colindantes, se deja un pequeño huelgo de $2 \mathrm{~cm}$, que resulta insuficiente en caso de sismo para absorber las deformaciones que se producen, habiéndose producido impactos entre bloques estructurales por resonancia, que han generado grandes daños en elementos constructivos de todo tipo.

Se han detectado procesos de «torsión» por un fenómeno difícil de explicar, que tiene que ver con la elevada distancia entre el centro de masas y el centro de rigidez de los edificios en esquina. En un edificio en esquina, las paredes medianeras (dos) arriostran perfectamente al edificio en sus dos planos, por tratarse de elementos bien apoyados en la estructura, con buena resistencia a cortante ( $\sin$ huecos) y que atan al edificio desde la cimentación a la coronación. Consiguientemente, estas medianeras (aunque sean de ladrillo) colaboran estructuralmente con la estructura principal del edificio y hacen que el punto más rígido del edificio venga a coincidir con el punto de intersección de las medianeras. Durante el sismo, se produce entonces la torsión del edificio con toda su masa en torno a este centro de rigidez, ocasionándose una tipología de daños por choques entre estructuras con edificios colindantes y torsiones que afectan a elementos constructivos.

Finalmente, se ha constatado el buen comportamiento estructural de algunas soluciones de diseño que se venían realizando en los últimos años para rigidizar los edificios en altura, tales como los pilares apantallados (de sección rectangular con un ancho mínimo del orden de $30 \mathrm{~cm}$ ) y las pantallas de hormigón (de cimentación a cubierta), coincidentes con los huecos de ascensor. Hay edificios en Lorca, construidos con estos sistemas estructurales que no han registrado daños estructurales ni constructivos. Son la prueba experimental evidente de que estos diseños especiales a sismo funcionan correctamente. 

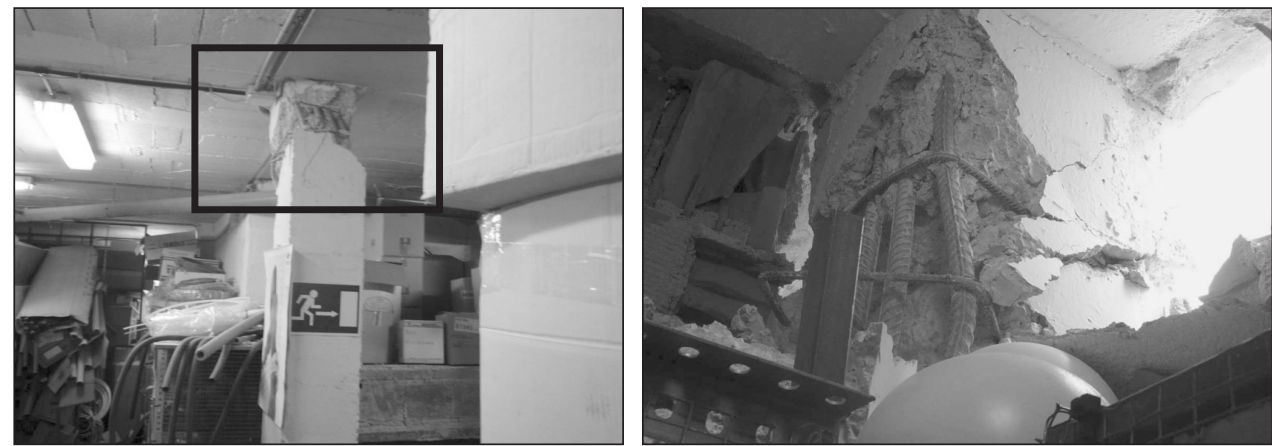

FIgURAS 18 y 19: A la izquierda, daños en la estructura: pilar de un sótano, degollado en su cabeza por la acción sísmica. A la derecha, detalle de otro pilar con el mismo efecto, en el que se observó un déficit de cercos.
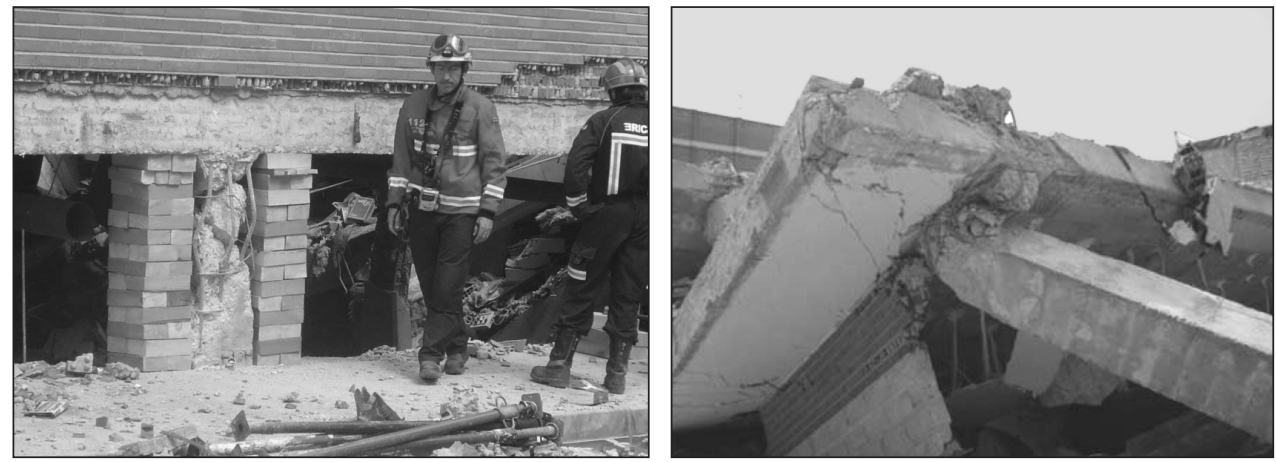

FIgURAS 20 y 21: A la izquierda, pilar corto, destruido por el sismo; este tipo de pilares, por su imposibilidad de oscilar, es el que resulta más afectado. A la derecha, rotura por la cabeza de un pilar, del edificio que colapsó completamente.
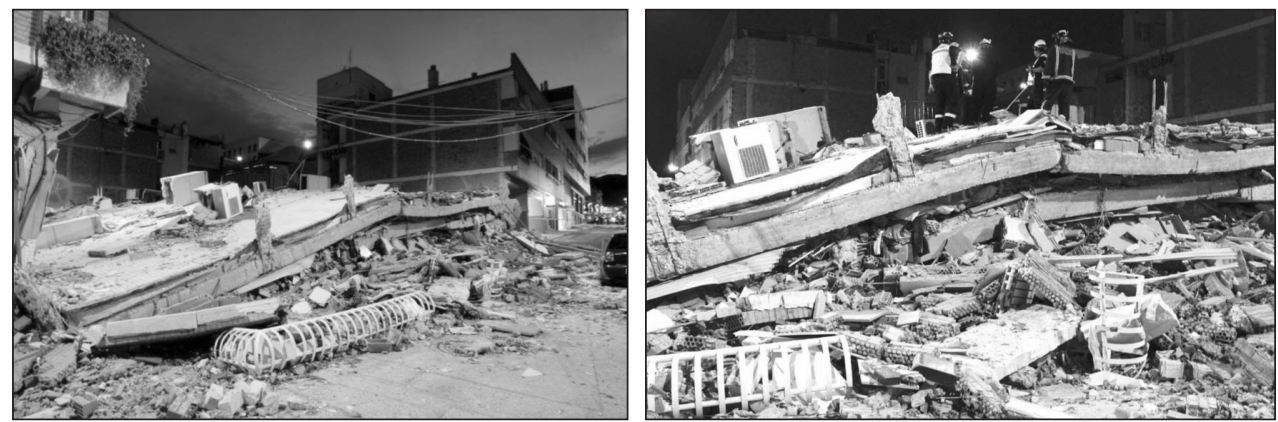

Figuras 22 y 23: Imágenes del edificio de la calle Infante Juan Manuel, $n^{\circ} 5$, único edificio colapsado en su estructura, con el clásico apilado de forjados, que nunca hasta ahora se había visto en España. Muchas de las imágenes de televisión de los daños del terremoto, pertenecían al mismo edificio. 


\subsection{Daños en elementos constructivos secundarios de albañilería}

Se ha constatado que la mayor parte de los daños materiales del terremoto no se han producido en las estructuras resistentes, sino en otros elementos constructivos (secundarios) que se apoyan en esas estructuras, tales como cerramientos de ladrillo de fachada, antepechos de ladrillo de cubiertas y balcones, falsos techos de escayola, carteles de locales comerciales, cierres de aluminio y cristal de terrazas, etc. A la fracturación y fisuración generalizadas de cerramientos y tabiques ha contribuido en gran medida su constitución a base de ladrillo. El ladrillo, en cualquiera de sus formatos y sistemas de construcción, produce elementos (paredes) de gran rigidez que, al no poder deformarse como sí lo hace la estructura de hormigón, se rompen, manifestando fracturas y fisuras, especialmente en la planta más rígida (la baja); por ello, locales comerciales y portales han sido los más afectados y son los daños que más se han visto en las imágenes distribuidas. Los elementos con tabiques modulares (tipo Pladur (C) han sido mucho menos alterados por este fenómeno, por contar con una estructura interior resistente, de acero.

En casos extremos, se produjo el desplome y derrumbe hacia la calle de los cerramientos, muy especialmente de antepechos (o petos) de terrazas, balcones, etc, por pérdida de equilibrio por su base de apoyo en la estructura. En España, en los últimos 50 años, se ha generalizado el cerramiento de ladrillo, apoyado sólo parcialmente en el borde de la estructura (de ordinario 2/3 del ancho del ladrillo), lo cual resulta adecuado para la acción vertical (el peso), pero muy peligroso en caso de terremoto, como se ha constatado en Lorca, pues este apoyo es insuficiente ante el empuje horizontal causado por el sismo que le hace perder el equilibrio y caer hacia la calle, originando cuantiosos daños materiales y personales, muertos.

Aunque aparece en pocas construcciones, hay que dejar constancia también del pésimo comportamiento de los cerramientos tipo «muros cortina» o «fachadas ventiladas», que han resultado ser incompatibles estructuralmente con el fenómeno sísmico.
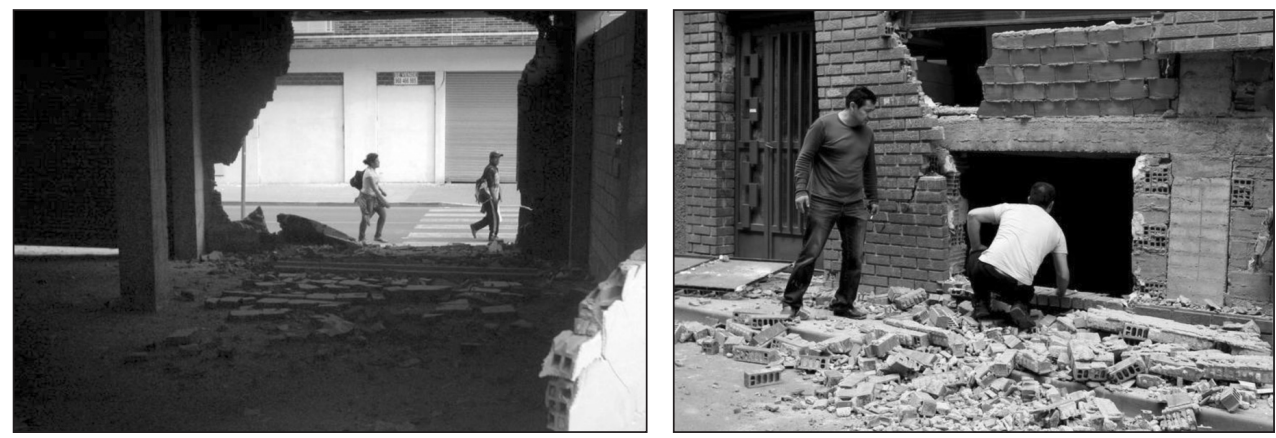

FIGURAS 24 y 25: Obsérvese en las plantas bajas el daño generalizado de los cerramientos, mientras las estructuras de los edificios permanecieron en pie. 

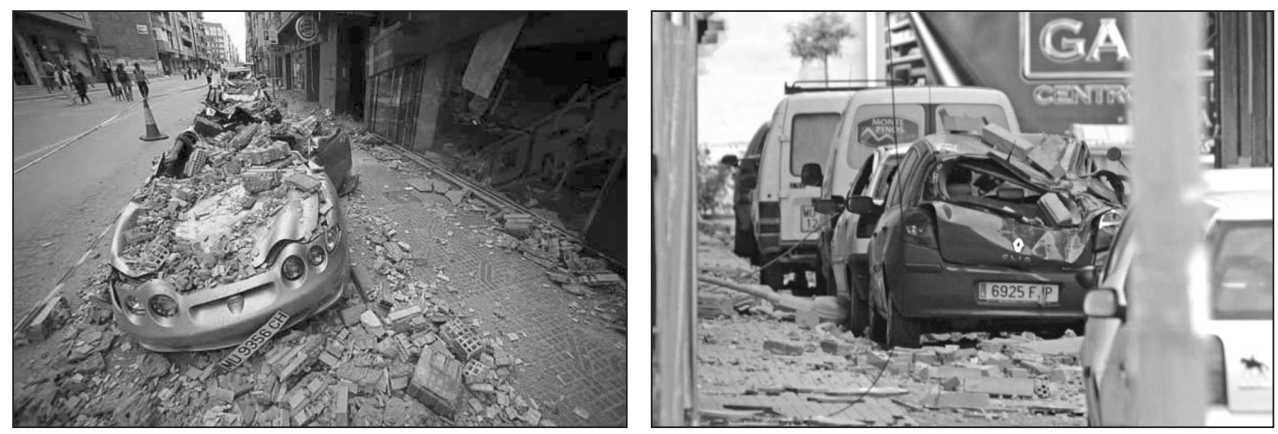

FIGURAS 26 y 27: Daños producidos en las aceras por el derrumbe generalizado de los antepechos de ladrillo de las cubiertas y de los balcones. Por este fenómeno se produjeron la mayor parte de las muertes, al caer los escombros sobre personas que salieron a la vía pública asustadas tras el primer terremoto.
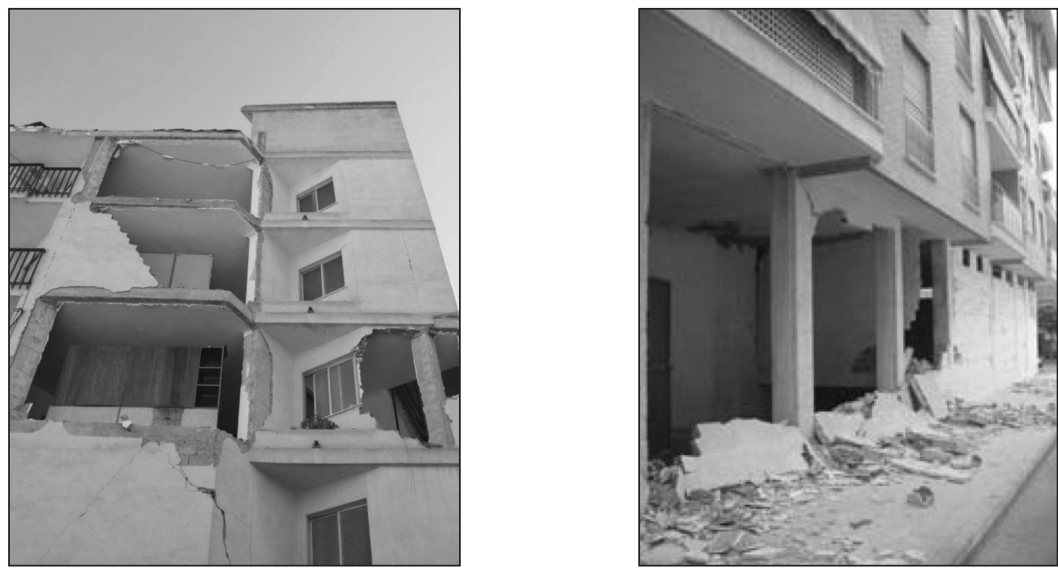

FIGURAs 28 y 29: A la izquierda, un ejemplo de edificio con cerramiento de ladrillo, sólo parcialmente apoyado en el borde del forjado. La estructura ha permanecido en pie cumpliendo las exigencias de la norma sísmica, pero los cerramientos se han derrumbado produciendo enormes daños materiales y riesgo de daños personales. A la derecha, un edificio en el que tanto estructura como cerramientos convencionales se comportaron correctamente, y lo que se derrumbó fue el «cerramiento provisional» con el que se tabicó los locales comerciales para su venta.
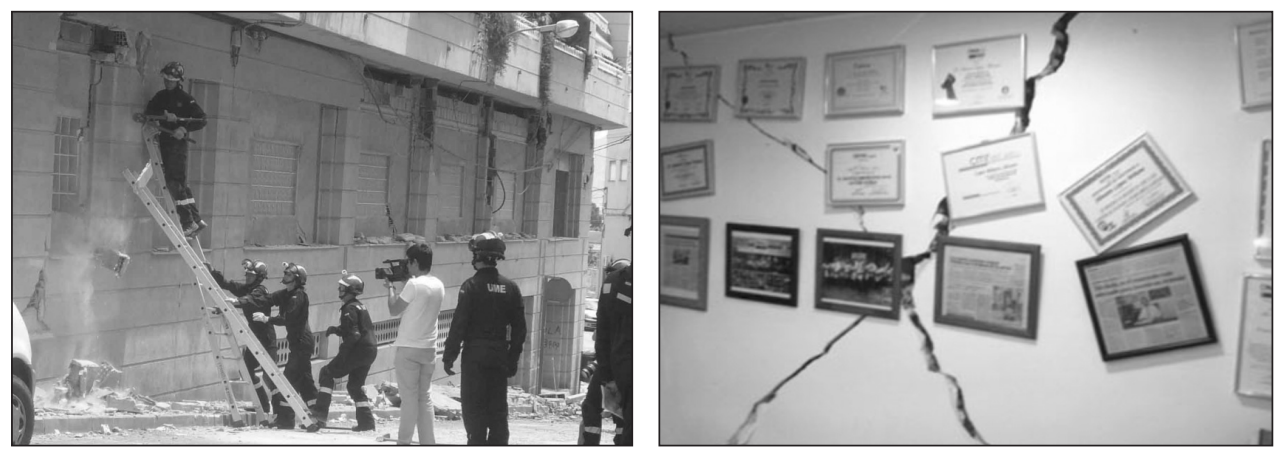

FIgURAS 30 y 31: A la izquierda, daños en los cerramientos, especialmente en las plantas bajas. A la derecha, grietas en aspa, en las tabiquerías interiores de ladrillo. 


\subsection{Daños personales}

La mayor parte de los daños personales se produjeron por la caída a la calle (a la acera) de cascotes, sobre los vecinos que salieron asustados de sus casas, tras el primer terremoto (terremoto premonitorio de las 15:05 horas). Con seguridad, si hubieran permanecido dentro de los edificios, el número de muertos habría sido menor.

A las 16:47 horas, cuando se produjo el sismo principal, las calles estaban llenas de personas. El hecho de que muchas de las calles de Lorca sean demasiado estrechas en relación a la altura excesiva de edificios de 4 a 6 plantas, hizo que los fragmentos de cerramientos de los edificios, que perdieron el equilibrio y cayeron a la calle, se distribuyeran por toda la vía pública, atrapando a las personas, que encontraron la muerte por los fragmentos de cascotes lanzados como proyectiles.

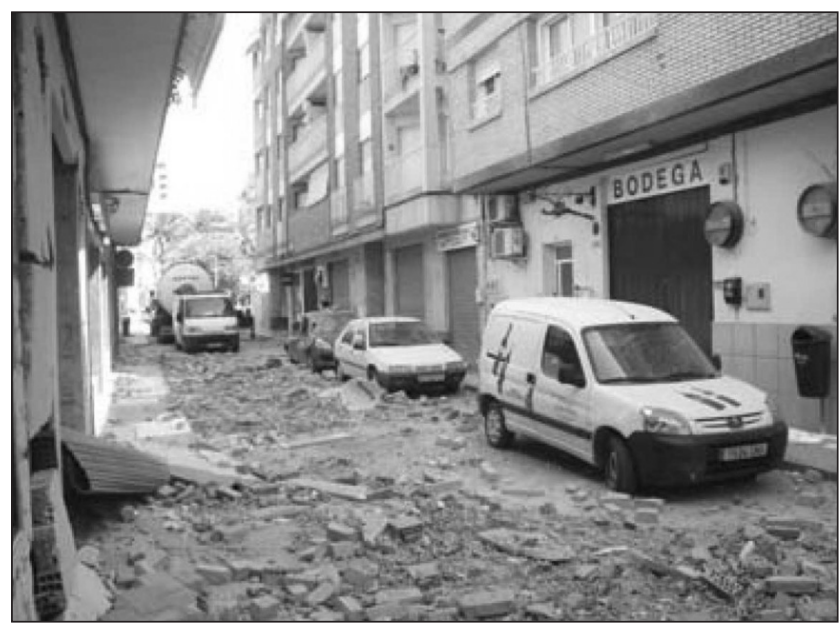

Figura 32: Fotografía de la calle Galicia, en la que se produjeron varios de los fallecidos. Obsérvese cómo quedó la calle con los fragmentos de cerramientos caídos de los edificios.

\section{La seguridad antisísmica de los edificios en España}

\subsection{Normas sismorresistentes y mapas de riesgo sísmico. Cambios futuros}

La normativa sismorresistente es de aplicación a los edificios de nueva planta, construidos a partir de su publicación, pero no a los edificios anteriores, como es lógico. La primera norma sismorresistente española fue aprobada en 1968 por una comisión ${ }^{11}$, creada en 1962, a raíz del terremoto de Albolote (1956). Desde entonces se ha venido actualizando periódicamente, siendo la actual norma la NCSE-02 (Norma de Construcción Sismorresistente). Es una buena norma estructural, como toda la normativa española de estructuras, que es de ámbito estatal y de aplicación en todo el territorio nacional.

Una norma sísmica tiene por principal objeto que las estructuras no colapsen en caso de sismo. No quiere ello decir que tengan que soportar «a toda costa» el fenómeno sís-

11 Existieron unas primeras determinaciones sísmicas, introducidas el mismo año 1962 en la norma MV101, que eran de aplicación, exclusivamente, para las obras oficiales promovidas por el Ministerio de la Vivienda. 
mico, sino que han de mantener la seguridad de las personas que albergan para que no se produzcan efectos desproporcionados con relación al terremoto. Se ocupa menos de los elementos constructivos secundarios.

En España, todos los edificios se verifican para la acción sísmica, aunque de diferente manera, según las zonas. Las estructuras se calculan para todo su peso y el de todos los elementos constructivos e instalaciones, toda la sobrecarga, la nieve, el viento y el sismo, con unos valores que se multiplican por unos coeficientes de seguridad para mayorarlos, y se combinan para prever su concurrencia. Los arquitectos aplican la norma con la acción sísmica en las localidades en las que es de aplicación y el Colegio Oficial de Arquitectos se encarga, mediante el visado de los proyectos, de comprobar que la normativa se ha considerado. Es muy conveniente que esto siga siendo así. En un momento en el que se está barajando eliminar trámites administrativos de todo tipo «para agilizar burocracia y abaratar costes», es conveniente que la sociedad reconozca la importante labor que realizan estos colegios profesionales, porque se trata de un control que no se puede dejar en manos de pequeños ayuntamientos, porque carecen de medios, ni menos aún del mercado inmobiliario.

En España, los siniestros estructurales en los edificios son casi inexistentes y esto es debido a que las cosas se hacen bien en materia de seguridad estructural: hay profesionales titulados que proyectan los edificios y que dirigen sus obras, bajo el control colegial, y hay controles administrativos, que deben seguir existiendo en beneficio de la sociedad a la que van dirigidos.

En el caso de Lorca, puede haber existido un cierto incumplimiento efectivo de la norma en los edificios proyectados a partir de 2002, en los aspectos constructivos secundarios, porque la norma sismorresistente vigente (NCSE-02), ya introdujo sobre la anterior de 1994 un apartado (el 4.7) sobre «otros elementos de la construcción», en el que se establecía que «uno de los objetivos de la Norma (...) es una reducción sustancial de las usualmente cuantiosas pérdidas físicas y económicas, y sobre todo de víctimas, especialmente las que genera el daño a elementos no estructurales». Efectivamente, y aunque no existían antecedentes en España, este nuevo apartado de la norma ha resultado ser premonitorio, porque en el caso de Lorca se han registrado demasiados daños en estos elementos secundarios, que habrá que investigar en cuanto al efectivo cumplimiento de la norma en el proyecto y en la ejecución de obra en los edificios construidos desde 2002. El cumplimiento de estas determinaciones implicaría el cambio de determinadas soluciones constructivas tradicionales, en detrimento de elementos como el ladrillo.

La norma será seguramente revisada de nuevo, porque cada vez que se produce un acontecimiento que arroja datos nuevos sobre la seguridad de los edificios (estructuras en general, materiales estructurales, sismos, incendios, etc) las normas en España son inmediatamente modificadas por las «comisiones permanentes» que las redactan y revisan. En ese momento deberá abordarse la seguridad de los otros elementos constructivos (no estructurales), que son los que han producido los daños personales y las mayores pérdidas económicas en Lorca.

Lo primero que habrá que revisar de esta norma es el mapa de riesgo sísmico que en ella se incluye. Si observamos los mapas de las diferentes ediciones de la norma (1962, 1968, 1974, 1994 y 2002), vemos que sus valores han cambiado sensiblemente entre una y otra, lo que pone de manifiesto que, más que un mapa fiable, se trata de una especie de «pronóstico» cambiante, que en el caso del terremoto de Lorca ha previsto valores de sólo $1 / 3$ de los que realmente ha producido la naturaleza. Los geólogos deben investigar más en lo que denominan paleosismicidad (registro de terremotos históricos) y en el estudio de las fallas activas de la Península que, aunque no hayan registrado fenómenos sísmicos parecidos, sí que podrían registrarlos en el futuro. 


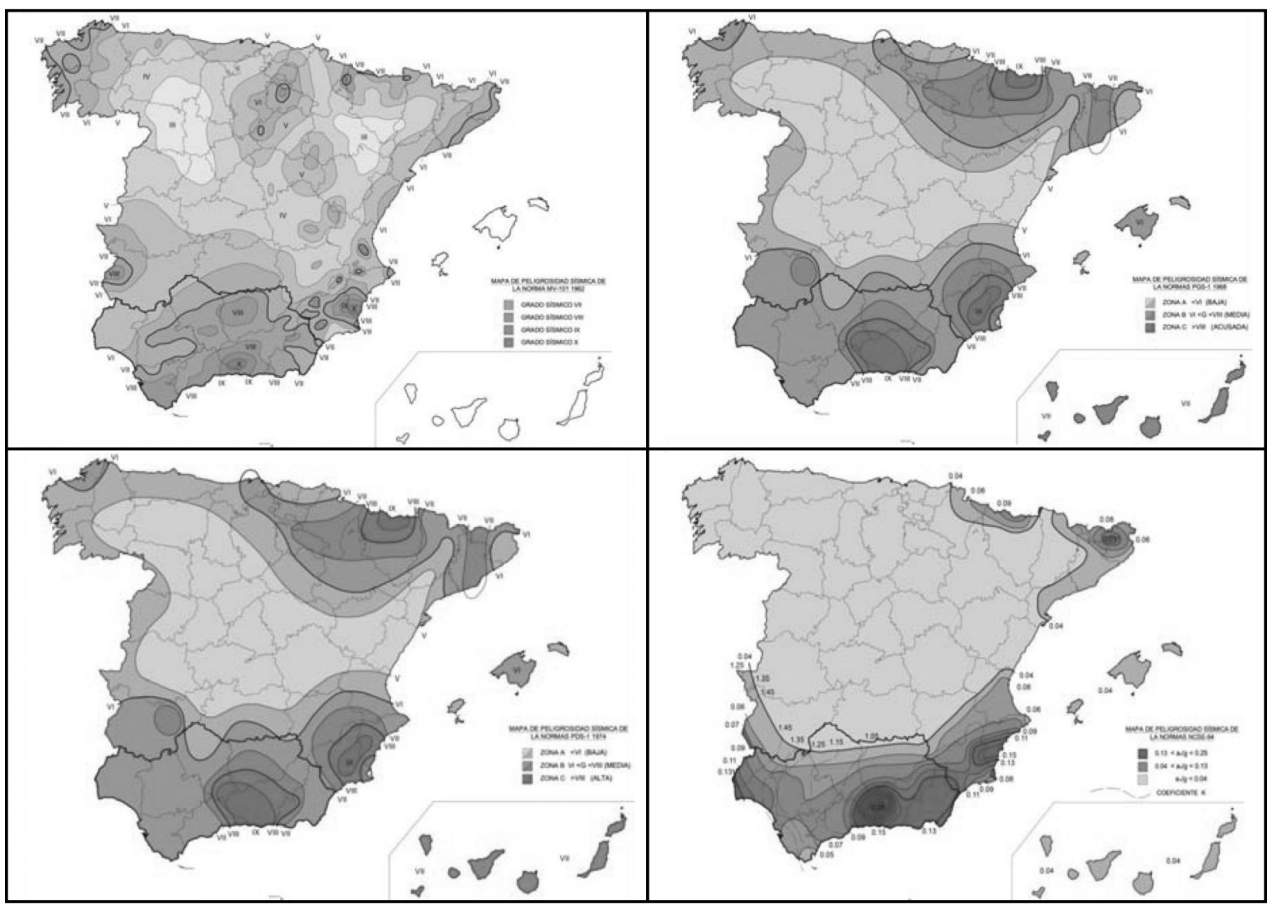

FIgURAS 33, 34, 35 y 36: Mapas de riesgo sísmicos anteriores al actual, correspondientes a las normas de 1962, 1968, 1974 y 1994. Obsérvese la variación de valores.

Estos estudios tal vez deberían desembocar en la adopción de coeficientes de seguridad más altos, como se hace en edificación. Es inasumible que el coeficiente de seguridad sísmico sea «la unidad» cuando se ha puesto de manifiesto una gran incertidumbre en los valores efectivamente registrados. El terremoto de Lorca habría quedado dentro del coeficiente de seguridad de 3 que se emplea en el cálculo de cimentaciones, dada la incertidumbre del terreno, en cumplimiento del Código Técnico de la Edificación. Por la falta de garantía en la previsión de los fenómenos sísmicos, sería razonable aplicarle un coeficiente comparable de seguridad, de no conseguirse datos geológicos más fiables.

\subsection{Seguridad estructural antisísmica de los edificios modernos}

Las normas sismorresistentes tienen por objeto que las estructuras se mantengan en pie durante el sismo, de manera que protejan a sus ocupantes hasta que el edificio pueda ser evacuado. Esta exigencia es la misma en todas las normas sísmicas del mundo desarrollado.

Tras el análisis del terremoto de Lorca sobre las estructuras modernas, los datos objetivos son los siguientes:

- Los edificios nuevos de Lorca (construidos a partir de la norma sísmica) fueron calculados por los arquitectos para una aceleración sísmica de $0,12 \mathrm{~g}$, que es la que viene indicada en el mapa de riesgo sísmico de la norma NCSE-02 publicado en el B.O.E. 
- La aceleración sísmica ${ }^{12}$ que se produjo en el terremoto de Lorca fue de $0,37 \mathrm{~g}$, según los datos del Instituto Geológico Nacional (Cabañas et al, 2011; 21), cuyos acelerógrafos están instalados en la misma ciudad de Lorca.

- De los 3.000 edificios que podemos denominar «nuevos» con estructuras de hormigón, sólo uno ${ }^{13}$ resultó colapsado, que es el edificio de la calle Infante Juan Manuel $\mathrm{n}^{\mathrm{o}} 5$.

En consecuencia, las únicas conclusiones posibles son:

- El buen comportamiento en general de las estructuras de los edificios nuevos, que han superado, de manera generalizada, un sismo de acción triple de la prevista en el cálculo.

- La necesidad de revisar los datos geológicos, puesto que no es de recibo un error semejante en la aceleración sísmica. Y, en el caso en que no sea técnicamente posible obtener datos más fiables, introducir en la normativa de seguridad estructural, un coeficiente de seguridad que absorba la incertidumbre de los datos sísmicos, como se hace en seguridad estructural de edificación, por ejemplo, con el terreno de cimentación.

Con respecto a los elementos secundarios de albañilería, que son los que han producido los cuantiosos daños materiales y personales, se hace necesario el cumplimiento de las determinaciones que para estos elementos se han empezado a adoptar en las normas a partir de 2002 (NCSE-02), 2006 (CTE-DB-SE-F).

\subsection{Recomendaciones para los edificios del patrimonio monumental}

De las conclusiones derivadas de la vulnerabilidad de los edificios históricos de Lorca ante el sismo de 2011 y de los cuantiosos daños en edificios patrimoniales, con rehabilitaciones recientes, que habían incorporado prácticas restauradoras incompatibles con sus fábricas, deberían extraerse conclusiones aplicables a las nuevas estrategias de prevención de daños en las estructuras históricas y en las intervenciones restauradoras y rehabilitadoras, para minimizar los efectos de nuevos seísmos.

En este sentido entendemos de interés las reflexiones anteriores sobre el comportamiento de los edificios patrimoniales de estructuras de fábrica, de cara a los actuales proyectos de estabilización estructural y rehabilitación del patrimonio.

Promovido por la Dirección General de Bellas Artes y Bienes Culturales del Ministerio de Cultura, fue aprobado el Plan Director de Recuperación del Patrimonio Cultural de Lorca, por Consejo de Ministros de 28 de octubre de 2011, bajo la coordinación del arquitecto Eduardo Barceló, para la restauración de 75 edificios de la ciudad, como herramienta para la coordinación de las administraciones y planificación de las intervenciones con presupuestos extraordinarios por montante de 51 millones de euros (Ministerio de E.C.D., 2011).

Para abordar la recuperación por el Plan Director se han elaborado fichas independientes para cada uno de los elementos con descripción de sus características, daños producidos por el terremoto y propuestas de intervención, así como la valoración de costes de restauración y la programación temporal. Los edificios singulares, considerados relevantes del patrimonio histórico-cultural de Lorca y su término, han sido seleccionados por el criterio

12 «Los valores máximos de PGA registrados en Lorca en los dos primeros terremotos (270 y $358 \mathrm{~cm} /$ $\mathrm{sg}^{2}$ respectivamente), son los más grandes, jamás registrados (instrumentalmente) en la Península Ibérica, según consta en las bases de datos del IGN». (Cabañas et al., 2011: 38)

13 Según el propio informe oficial «... el edificio que colapsó, teniendo en cuenta el gran número de edificios existentes en Lorca y sus alrededores, no tiene valor estadístico» (Cabañas et al., 2011: 29). 
de catalogación como Monumentos Nacionales y Bienes de Interés Cultural ${ }^{14}$, o por estar insertos dentro del Conjunto Histórico-Artístico con protección de Grado $1^{15}$ y de Grado $2^{16}$.

\subsection{Recomendaciones constructivas para los edificios actuales}

Una vez comprobado que las estructuras de los edificios han superado, con carácter general, un sismo del triple de intensidad de la prevista por el mapa de riesgo sísmico, procedería una revisión de la norma sobre los elementos constructivos secundarios, que son los que han periclitado, produciendo fallos no de SEGURIDAD ESTRUCTURAL, sino de SEGURIDAD FÍSICA, que es la que ha producido los daños personales. Las recomendaciones constructivas son:

- Eliminar los petos de las cubiertas y balcones, sustituyéndolos por otras soluciones como las barandillas, más ligeras y resistentes a la acción sísmica.

- Sustituir los tabiques de ladrillo por otras soluciones como las particiones modulares o de yeso laminado (tipo Pladur(C), dotadas de estructura entramada interna.

- Verificar el correcto apoyo de todos los cerramientos en los bordes de las estructuras y su arriostrado, por ejemplo, sujetando la hoja exterior a los pilares.

- Sustituir los falsos techos de placas rígidas de escayola por otras soluciones menos frágiles.

En cuanto a la estructura propiamente dicha, en los edificios nuevos, conviene recordar las recomendaciones generales sísmicas, que siguen siendo válidas tras la experiencia de Lorca:

A) Recomendaciones de diseño estructural:

- Realizar un buen diseño estructural regular porticado, lo más simétrico posible.

- Rigidizar en altura los edificios más esbeltos, con soluciones como pilares apantallados alternados o núcleos de arriostramiento en zonas de ascensores.

- Evitar la existencia de plantas de muy diferente peso.

- Dotar de un mayor atado a los cimientos con vigas.

- Evitar la existencia de elementos locales, excesivamente rígidos, sobre todo en las plantas bajas, tales como pilares de pequeña altura, que por su escasa capacidad de deformación resultan cizallados por la acción sísmica.

14 M.N. y B.I.C. Castillo: Torre del Espolón y tramos de la muralla. Castillo: Torre Alfonsina. San Clemente. Castillo: derrumbe rocoso del basamento de la muralla. Porche de San Antonio. Muralla manzana 7. Palacio de Guevara. Colegiata de San Patricio. Iglesia y Convento de San Francisco. Colegio de San Francisco. Iglesia de Nuestra Señora del Carmen. Iglesia de San Mateo. Casino Artístico y Literario. Palacio de los Condes de San Julián. Torre de Mena-La Hoya. Teatro Guerra. Casa Privada en Teatro Guerra. Palacio Huerto Ruano.

15 GRADO 1: Ayuntamiento. Iglesias altas de San Juan. Santa María y San Pedro. Iglesia de Santiago. Iglesia de Santo Domingo y Capilla del Rosario. Claustro de Santo Domingo. Ermita de San Roque. Ermitas del Monte Calvario y Cristo de la Misericordia. Iglesia de San José. Iglesia Santuario Virgen de las Huertas. Iglesia de San Diego-Barrio de San Diego. Iglesia de San Cristóbal-Barrio de San Cristóbal. Panteones del Cementerio de San Clemente. Iglesia del Cementerio de San Clemente. Chimenea carretera Caravaca. Iglesia de San JoséPedanía de El Consejero. Iglesia de la Asunción de la Parroquia. Casas del Consejero y Molino del Escarambrujo.

16 GRADO 2: Portada Convento de la Merced. Convento de la Merced-Sede Urbanismo. Museo Arqueológico Casa Salazar-Rosso. Plaza de Toros-Sutullena. Casa de los Irurita. Casa Guevara. Casa de las Arcas. Casa de los Cachá. Casa de los Mula. Casa de Evaristo Sánchez. Casa de los O’Shea. Juzgados Casa del Corregidor. Archivo Municipal-Antiguo Pósito. Casa Quiñoneros. Casa Gimeno Baduel. Casa de los Aragón. Chalet de los Olivares. Casa de los Alburquerque. Estación Renfe-Sutullena, Depósito carcelario-Antiguo Almudín. Casa Villaescusa. Casa de los Calderones. Antigua Casa Paso Blanco. Antiguo Colegio de la Purísima Concepción. Salas Capitulares San Patricio. Casa Rubira. Casa de los Marín-Ponce de León. Casa de los Selgas. Torreón de los García Alcaráz. Granero Decimal. Edificio Bertrand. Casa de los Pallares. Cámara Agraria. Casa López de Teruel. Casa del Paso Azul-Cariátides. Colegio de las Mercedarias. Casa de la Calle de la Cava. Casa del Obispo Badén. 
B) Recomendaciones de armado de secciones de hormigón:

- Reforzar los cercos en la cabeza y en la base de los pilares, sobre todo en las plantas más bajas, que son las que tienen menor posibilidad de oscilación, como prevé la norma, y cuidar la ejecución de los estribos en las vigas, sobre todo en las zonas próximas a los nudos.

- Aumentar la cuantía de armaduras es algo que con la vigente instrucción de estructuras de hormigón (EHE-08) se cumple siempre, pero conviene reiterarlo.

- Asegurar el anclaje de las armaduras al hormigón.

- Prolongar en las plantas bajas la mayor parte de la armadura de positivo de las vigas hasta los pilares, del orden de $2 / 3$ del armado máximo de positivo.

- Utilización de los aceros más dúctiles (SD).

$\mathrm{Y}$ en general, el cumplimiento de la norma en todas sus especificaciones de diseño y constructivas. En la edificación en España no se falla en la norma, sino en la verificación de su cumplimiento. Se detectan más errores en la ejecución física de las obras que en su proyecto y cálculo.

La conclusión final de este artículo es que se debe seguir investigando en la dinámica de los riesgos naturales y de la vulnerabilidad sísmica, e informar a la población de las medidas que ha de adoptar en caso de fenómenos sísmicos. En lo que respecta a la estructura de los edificios, Lorca ha puesto de manifiesto que las cosas se han hecho bien, aunque se puede y se debe mejorar en aspectos de índole constructiva, en elementos secundarios y en la revisión de los valores del mapa sísmico. El rico patrimonio histórico, inmueble y mueble, podrá rehabilitarse con mucho esfuerzo económico, para que pueda seguir cumpliendo con su doble papel de afirmador de las señas de identidad y de producto turístico-cultural (Lorca: taller del tiempo), pero las pérdidas humanas son irremplazables. A su memoria dedicamos este artículo.

\section{Bibliografía}

AA. VV. (2011): IV Congreso Nacional sobre Ingeniería Sísmica. Asociación Española de Ingeniería Sísmica (AEIS) y Universidad de Granada, ETSICCP, Granada, 18 a 20 de mayo. (Ponencia y Debate dedicados a los terremotos de Lorca).

ARGEA CONSULTORES, S. L. Atlas de la Vulnerabilidad Urbana en España. Ministerio de Fomento, Madrid, 2012. (enero).

http://siu.vivienda.es/portal/index.php?option=com_content $\&$ view=article $\& i d=103 \& I t e m$ $\mathrm{id}=157 \&$ lang $=\mathrm{es}$

AYALA, F. J. y OLCINA, J. (Coords.). (2002): Riesgos naturales. Ariel, Barcelona, 2002. $1.512 \mathrm{pp}$.

AYUNTAMIENTO DE LORCA. (2000): Plan Especial de Protección y Rehabilitación Integral en el Conjunto Histórico de Lorca (P.E.P.R.I.L.). Lorca (Arquitecto redactor: Simón Ángel Ros Perán).

ARANGO GONZÁLEZ, J. R. (2003): Introducción al estudio de la vulnerabilidad sísmica de los edificios históricos de Granada. Editorial de la Universidad de Granada, Granada. 149 pp.

BONELLI, J. y CHACÓN, L. (1961): «Estudio de la sismicidad en la zona murcianoalicantina», en Instituto Geográfico Cat. 1961. 19 pp.

BONELLI, J. y ESTEBAN, L. (1958): «El sismo de Albolote-Atarfe de 19 de abril de 1956», en Instituto Geográfico Cat., 1958. 16 pp.

CABAÑAS, L.; CARREÑO, E.; IZQUIERDO, A.; MARTÍNEZ, J. M.; CAPOTE, R.; MARTÍNEZ, J.; BENITO, B.; GASPAR, G.; RIVAS, A.; GARCÍA, J.; PÉREZ, R.; 
RODRÍGUEZ, M. A.; MURPHY, P. (2011): Informe del sismo de Lorca del 11 de mayo de 2011. IGN, Madrid, julio. 138 pp.

CALVO GARCÍA-TORNEL, F. (1984): «Riesgo sísmico y sismicidad histórica en el SE peninsular», en Geographica, XXVI. CSIC, Madrid, pp. 121-130.

CALVO GARCÍA-TORNEL, F. (2001): Sociedades y territorios en riesgo. Ediciones del Serbal, Madrid. 186 pp.

CAMPOS ROMERO, M $^{\mathrm{a}}$ L. (1991a): «Los riesgos naturales y su incidencia en la Península. El riesgo sísmico y de tsunamis en el suroeste español», en XII Congreso Nacional de Geografía. Sociedad y Territorio. Asociación de Geógrafos Españoles y Universitàt de València, Valencia, pp. 139-145.

CAMPOS ROMERO, M ${ }^{\mathrm{a}}$ L. (1991b): «Tsunami Hazard on the Spanish coasts of the Iberian Peninsula», en Science of Tsunami Hazards, The International Journal of the Tsunami Society, vol 9, $\mathrm{n}^{\circ}$ 1, Especial Issue, Honolulu, Hawaii, (U.S.A), pp. 83-91.

CIRUJANO, C. y DE SOUSA, A. L. (Coords.). (2011): Jornadas de Patrimonio en Riesgo. El seísmo de Lorca. Ministerio de Educación, Cultura y Deporte, Consejería de Cultura y Turismo de la Región de Murcia, Lorca. (26-28 de septiembre). (Inéditas).

COLEGIO DE INGENIEROS DE CAMINOS, CANALES Y PUERTOS. (2011): Jornada de Ingeniería Sísmica. El terremoto de Lorca. Murcia, (junio).

FEILDEN, B. y ALBA, A. (1981): «Los terremotos y los edificios históricos», en Sexta Asamblea General de ICOMOS. ICOMOS, Roma, pp. 481-497.

FERICHE et al. (2011): Informe de efectos del terremoto de Lorca en las edificaciones. Universidad de Granada, Instituto Andaluz de Geofísica. Granada, 30 p. Disponible en http://www.ugr.es/ iag/terremoto lorca.html

GIL OLCINA, A. (1968-1969): «La ciudad de Lorca. (Notas de Geografía urbana)», en Papeles del Departamento de Geografía, 1. Universidad de Murcia, Murcia, pp. 79-110.

GIL OLCINA, A. (1980): Ciclo de temas lorquinos. Lorca del siglo XVI al XVIII. Introducción a la historia de una ciudad del sureste. Murcia, 30 pp.

GIBER-ROBLES, J.L.; SILVA P.G.; PÉREZ-LÓPEZ, R.; RODRÍGUEZ-PASCUA, M. A.; LARIO, J.; BARDAJÍ, T. (2011): Evaluación del daño sísmico en edificios históricos y yacimientos arqueológicos: aplicación al estudio del riesgo sísmico. Proyecto EDASI, Fundación MAPFRE, Madrid. (En prensa).

HERRAIZ, M. y MEZCUA, J. (1979): «Aplicación del análisis espectral al sismo de Lorca del 6 de junio de 1977. Determinación de los parámetros focales», en III Asamblea Nacional de Geodesia y Geofísica. IGN, T. I. Madrid, pp. 395-417.

HERVÁS, J. Ma . y SEGOVIA, A. (1989): Arquitectura y color en Murcia. Región de Murcia, Consejería de Política Territorial y Obras Públicas, Murcia. 98 pp.

IBARGÜEN, J. y RODRÍGUEZ, T. (1996): «Peligrosidad sísmica en la Región de Murcia», en Sexto Congreso Nacional y Conferencia Internacional de Geología Ambiental y Ordenación del Territorio / 6th Spanish Congress and International Conference on Environmental Geology and Land-Use Planning. Universidad de Granada, Granada, pp. 407-425.

INSTITUTO GEOLÓGICO Y MINERO DE ESPAÑA. (1988): Estudio de Riesgos por Desprendimientos en el Cerro del Castillo de Lorca. IGME, Madrid.

INSTITUTO GEOLÓGICO Y MINERO DE ESPAÑA. (1992): Estudio de Peligrosidad y Vulnerabilidad Sísmica en Lorca y su Término Municipal. IGME, Madrid.

INSTITUTO VALENCIANO DE LA EDIFICACIÓN. (2011): Jornadas. Criterios de diseño estructural frente a sismo y evaluación de daños. La experiencia recogida del sismo de Lorca. El Plan Especial frente a Riesgo Sísmico de la Comunitat Valenciana. Generalitat Valenciana, I.V.E., Valencia. (29-30 de noviembre). (Inéditas). 
LÓPEZ MARINAS, J. M. (1978) «Notas sobre la sismicidad histórica en el Sureste español», en Seminario sobre criterios para instalaciones nucleares y obras públicas, Instituto Geográfico Nacional, Madrid, pp. 67-82.

LÓPEZ MARINAS, J. M. (1978): «Terremotos en la Provincia de Murcia», en Hidroeléctrica Española. 1978. 15 pp.

LÓPEZ, F.; CALVO, F.; MORALES, A. (1986): Geografía de la Región de Murcia. Ed. Ketres, Barcelona. 283 pp.

LÓPEZ, F.; GÓMEZ, A.; TELLO, B. (1989): «El relieve». Geografía de España, I. Geografía física. E. Planeta, Barcelona, pp. 194 y ss.

MARTÍNEZ DÍAZ, J. J. (1999): «Sismotectónica de la falla de Alhama de Murcia. Implicaciones sismogenéticas del terremoto de Lorca de junio-1977 (Mb: 4,2º)», en Estudios Geológicos, 65. Madrid, pp. 251-266.

MARTÍNEZ GUEVARA, J. B. (2011): «Sismos del 11 de mayo de 2011 en Lorca», en Papeles de Geografía, $\mathrm{n}^{\circ}$ 53-54. Universidad de Murcia, Murcia, pp. 199-213.

MARTÍNEZ RÍOS, C. (2007): «El Plan Especial de protección de la Muralla de Lorca». Memorias de Patrimonio 2003-2005. Intervenciones en el Patrimonio Cultural de la Región de Murcia, 7. Murcia, pp. 413-418.

MARTÍNEZ RODRÍGUEZ, A. (2004): «Lorca, ciudad amurallada», en Alberca, Revista de la Asociación de Amigos del Museo Arqueológico de Lorca, 2. Lorca, pp. 139-166.

MARTÍNEZ SOLARES, J. M. (2001): Los efectos en España del terremoto de Lisboa (1 de noviembre de 1755). Ministerio de Fomento, Dirección General del Instituto Geográfico Nacional, Monografía $\mathrm{n}^{\circ}$ 19, Madrid. 756 pp.

MARTÍNEZ, J. B. y FERNÁNDEZ, S. (1986): Catálogo sísmico de la región de Murcia. (Sismicidad histórica hasta el siglo XVIII). Instituto Geográfico Nacional, Madrid. (Informe interno).

MARTÍNEZ, J. M. y MEZCUA, J. (2002): Catálogo sísmico de la Península Ibérica (880 a.C.-1900). Instituto Geográfico Nacional, Monografía 11. Madrid.

MARTÍNEZ, J. J.; RODRÍGUEZ-PASCUA, M. A.; PÉREZ, R; GARCÍA, J.; GINER, J. L.; MARTÍN-GONZÁLEZ; RODRÍGUEZ, M.; ÁLVAREZ. J. A.; INSÚA, J. M. (2011): Informe geológico preliminar del terremoto de Lorca del 11 de mayo del año 2011 (5,1 Mw). Instituto Geológico y Minero de España, Grupo de Tectónica Activa, Paleosismicidad y Riesgos Asociados de la Universidad Complutense de Madrid, Universidad Autónoma de Madrid y Universidad Juan Carlos I de Madrid, Madrid. 47 pp.

MINISTERIO DE EDUCACIÓN, CULTURA Y DEPORTE. (2011): Plan Director para la Recuperación del Patrimonio Cultural de Lorca (Murcia). Dirección General de Bellas Artes y Bienes Culturales, I.P.C.E., Madrid (julio). 21 pp. + fichas de intervención.

MINISTERIO DE EDUCACIÓN, CULTURA Y DEPORTE. (2002): «Patrimonio en Riesgo: seísmos y bienes culturales», en Revista Patrimonio y Cultura en España, 6. Secretaría General Técnica, Madrid, 2012. 266 p.

http://es.calameo.com/read/000075335fb4cfb209514

MINISTERIO DE FOMENTO. (2002): NCSE-02, Norma de Construcción Sismorresistente: Parte General y de Edificación, R.D. 997/2002, BOE 11-10-2002, Madrid.

MINISTERIO DE LA PRESIDENCIA. (2008): EHE-08, Instrucción de Hormigón Estructural, R.D. 1247/2008, BOE, 22-10-2008, Madrid.

MENDARO, I. e IZQUIERDO, J. L. (1988-1989): «Aproximación al concurso de ideas para la rehabilitación y promoción del castillo de Lorca y su entorno», en ARQUIMUR, Arquitectura en Murcia, 7. Colegio Oficial de Arquitectos de Murcia, invierno, Murcia, pp. 55-66. 
MEZCUA, J. (1977): El terremoto de Lorca de 6 de junio de 1977. IGN. Publicación interna. Madrid. $22 \mathrm{pp}$.

MEZCUA, J. y MARTINEZ, J. M. (1983): «Sismicidad del área Ibero-Mogrebí», en Instituto Geológico Nacional, Pub. № 203. Presidencia del Gobierno, Madrid, 322 pp.

MURPHY CORELLA, P. (2006): «La Vulnerabilidad de la Edificación de la Región de

Murcia», en Riesgo Sísmico de la Comunidad Autónoma de la Región de Murcia (RISMUR), V. 3. Instituto Geográfico Nacional y D. G. Protección Civil CARM, 60 pp.

MURPHY CORELLA, P. (2011): «Quick Field Report: Lorca Earthquake 11th May 2011». EMSC-CSM report.

www.emsc-csem.org/Files/event/221132/lorca_quickfieldreport_lowres.pdf

REY PASTOR, A. (1951): «Estudio sismotécnico de la región sureste de España». Instituto Geográfico Cat. 52 pp.

ROLDÁN RUIZ, J. (2011): Parámetros de cálculo sísmico del terremoto de Lorca. Escuela de Arquitectura de la Universidad Católica San Antonio (UCAM), Murcia. (Inédito).

SALA JUST, J. (1972): Lorca, 1895-1936. Cámara Oficial de Comercio e Industria, Lorca. $263 \mathrm{pp}$.

SEGADO BRAVO, P. (2006): La Colegiata de San Patricio de Lorca. Ed. Universidad de Murcia, Murcia.

SOUSA, F. P. de. (1928): O Terramoto do $1^{\circ}$ de Novembro de 1755 em Portugal e um Estudo Demográfico. Tipografia do Comércio, Lisboa.

UGALDE, A. (Coord ${ }^{\mathrm{a}}$.). (2009): Terremotos. Cuando la tierra tiembla. CSIC, Colección Divulgación, Madrid.

VERA, A.; POZO, I; ROBLES, A.; NAVARRO, E. (2004): Plan Especial de Protección de la Muralla de Lorca. Ayuntamiento de Lorca, Lorca. 
